\title{
Next generation organofluorine containing blockbuster drugs
}

Jianlin Han, ${ }^{\mathrm{a}}$ Attila Márió Remete, ${ }^{\mathrm{b}}$ Luca S. Dobson, ${ }^{\mathrm{c}}$ Lorand Kiss, ${ }^{\mathrm{b}}$ Kunisuke Izawa ${ }^{\mathrm{d}}$, Hiroki Moriwaki ${ }^{\mathrm{d}}$, Vadim A. Soloshonok, ${ }^{* e, f}$ David O’Hagan*c

a Jiangsu Co-Innovation Center of Efficient Processing and Utilization of Forest Resources, College of Chemical Engineering, Nanjing Forestry University, Nanjing 210037, China.

${ }^{\mathrm{b}}$ Institute of Pharmaceutical Chemistry and Interdisciplinary Excellence Centre, Institute of Pharmaceutical Chemistry University of Szeged, H-6720 Szeged, Eötvös u. 6, Hungary.

${ }^{\mathrm{c}}$ School of Chemistry, University of St Andrews, St Andrews, Fife, KY16 9ST, UK.

${ }^{\mathrm{d}}$ Hamari Chemicals Ltd., 1-19-40, Nankokita, Suminoe-ku, Osaka, 559-0034, Japan.

${ }^{\mathrm{e}}$ Department of Organic Chemistry I, Faculty of Chemistry, University of the Basque Country UPV/EHU, Paseo Manuel Lardizábal 3, 20018 San Sebastián, Spain

${ }^{\mathrm{f}}$ IKERBASQUE, Basque Foundation for Science, María Díaz de Haro 3, Plaza Bizkaia, 48013 Bilbao, Spain

Keywords: fluorine; blockbuster drugs; disease states; synthetic routes; fluorinated pharmaceuticals

Abstract: The role of organo-fluorine compounds in modern health, food and energy related 
industries is widely-appreciated. The unique properties that fluorine imparts to organic molecules, stemming from its high electronegativity and stability when bound to carbon, finds it increasing being used in the development of new bioactivities. Around 25\% of the current blockbuster drugs contain fluorine and this number is increasing to well above 30\% for recent FDA approvals. In this Review we highlight a selection of the most successful organo-fluorine drugs, that have achieved blockbuster status, namely, sitagliptin (diabetes), sofosbuvir (hepatitis C), emtricitabine (HIV), glecaprevir/pibrentasvir (hepatitis C), elvitegravir (HIV), dolutegravir (HIV), bictegravir (HIV), efavirenz (HIV), enzalutamide (prostate cancer), aubagio (immunomodulatory) and paliperidone palmitate (schizophrenia). For each compound we discuss their discovery, their relevant disease state and how they are made, emphasizing the source of fluorine-containing moieties, and where known, their mode of action.

\section{Introduction}

Since the seminal development and introduction to the clinic of fludrocortisone (1) (Figure 1) [1] in 1953, the synthesis of organo-fluorine compounds for medicinal chemistry has grown from a rare and highly specialized activity to a status now where selective fluorinations of lead compounds are explored de rigueur in all front line drug development programmes. The high electronegativity of fluorine, its ability to form stable bonds to carbon and its compact size, offer a greater range of isosteric replacements (eg F for $\mathrm{H}$ ) or electronic tunability than any other element, and this has elevated the role of fluorine in all areas of bioactives discovery [2]. It is quite remarkable that fluorine-containing compounds now constitute around $25 \%$ of small molecule drugs in the clinic. Fluorine-scans and fluorine-editing are now fully embedded activities in medicinal chemistry 
explorations and this is having a major influence in contemporary organic chemistry. The international methodology development community, largely based in academia, are increasingly turning their focus towards innovative approaches to incorporating fluorine and fluorine containing motifs into organic chemistry scaffolds. This is driven by the requirement of big pharma to generate more and more diverse chemical libraries, with a higher frequency of fluorinated entities, to accelerate innovation. This is a golden age and there is no sense that the fluorine boom has peaked and when and where it may level out in drug discovery.

Although developments of organo-fluorine compounds in healthcare are relatively regularly reviewed [3] we are stimulated after a decade to provide an update to the 2010 article in the Journal of Fluorine Chemistry entitled "Fluorine in health care: Organofluorine containing blockbuster drugs" [4]. This article uniquely focused on the most successful fluorine containing drugs 'by sales' at that time. This particular focus appears to have been appreciated by those researchers and students reviewing the topic and complements other approaches which classify by structure, the frequency of organofluorine motifs, pharmacokinetic strategies, fluorine chemistry/methodology, disease states etc., and this overtly commercial criteria offers another angle for emphasising the impact and importance of organofluorine chemistry more generally.

Those drugs, that during their product lifetime, attained the status of sales of $\$ 1.0$ billion dollars or greater per annum are often referred to as "blockbuster drugs", and in this Review we highlight the more recent entries of organofluorine drugs in this category. This should not of course be the only definition of the success of a medication. The Pfizer statin, Lipitor (2) which is used to prevent cardiovascular disease [4], was highlighted in the 2010 review [4] and is considered the most profitable drug of all time, with sales exceeding $\$ 120$ billion during its patentable life time. It came 
off patent in 2011, and at that time generic manufacturers began production and dramatically reduced its market value. Although Lipitor lost its position as a leading revenue generator, it remains amongst the most prescribed drug in the world (in 2019) and still an outstanding success in prophylactic healthcare. However the anticipation of sales through patent lifetimes is what drives innovation in the pharmaceutical industry and therefore we feel that this approach merits some attention and is of general interest.

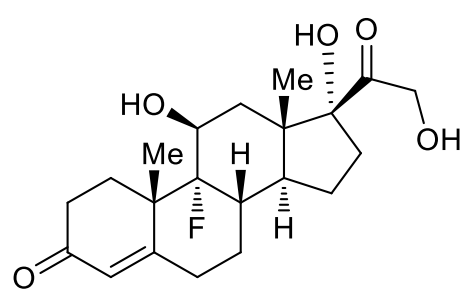

Fludrocortisone (1)<smiles>CC(C)c1c(C(=O)Nc2ccccc2)c(-c2ccccc2)c(-c2ccc(F)cc2)n1CC[C@H](O)C[C@@H](O)CC(=O)O</smiles>

Lipitor (2)

Figure 1. Structures of fludrocortisone (1) and Lipitor (2).

For the present review article, we have selected the current top twelve fluorine containing compounds, based on their sales rankings in 2018 or 2019. These include (Figure 2), teriflunomide (3) (immunomodulatory), sitagliptin (4) (diabetes), sofosbuvir (5) (hepatitis C), paliperidone palmitate (6) (schizophrenia), glecaprevir/pibrentasvir (7 and 8) (hepatitis C), elvitegravir (9) (HIV), enzalutamide (10) (prostate cancer), dolutegravir (11) (HIV), bictegravir (12) (HIV), emtricitabine (13) (HIV) and efavirenz (14) (HIV). Each compound is considered individually where their modes of action and then their synthetic routes are described, and with an emphasis on the source of the fluorine-containing moieties. 
<smiles>C/C(O)=C(\C#N)C(=O)Nc1ccc(C(F)(F)F)cc1</smiles>

Aubagio (Teriflunomide)

(3)

$\$ 2.1$ billion

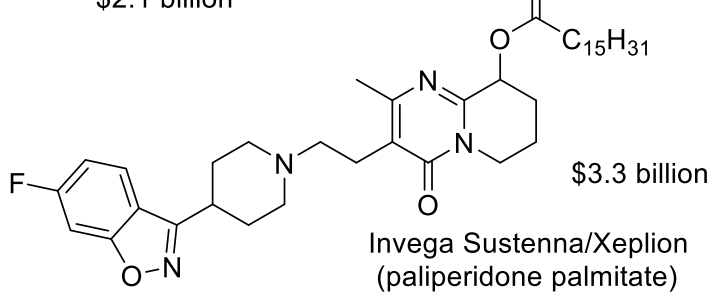

(6)

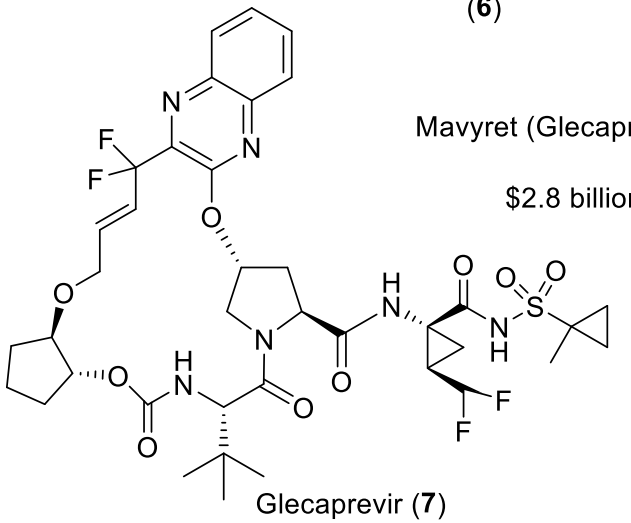

Glecaprevir (7)<smiles>N[C@@H](CC(=O)N1CCn2c(nnc2C(F)(F)F)C1)Cc1cc(F)c(F)cc1F</smiles>

Sitagliptin (4) $\$ 3.4$ billion<smiles>CC(C)OC(=O)[C@H](C)NP(=O)(OCC1OC2C(O)C(O)C1(F)C2O)Oc1ccccc1</smiles>

$\$ 1.9$ billion<smiles>Fc1ccc(C2CCNCC2)cc1</smiles>
ir/Pibrentasvir)<smiles>COC(=O)N[C@H](C(=O)N1CCC[C@H]1c1nc2cc([C@H]3CCC(c4cc5nc([C@@H]6CCCN6C(=O)[C@@H](NC(=O)OC)C(C)OC)[nH]c5cc4F)N3C(=S)I)c(F)cc2[nH]1)C(C)C</smiles><smiles>COc1cc2c(cc1Cc1cccc(Cl)c1F)c(=O)c(C(=O)O)cn2C(CO)C(C)C</smiles><smiles>CNC(=O)c1ccc(N2C(=S)N(c3ccc(C#N)c(C(F)(F)F)c3)C(=O)C2(C)C)cc1F</smiles>
Xtandi (Enzalutamide) (10) $\$ 4.5$ billion<smiles>CCO[C@@H](CO)Cn1cc(F)c(N)nc1=O</smiles><smiles>C[C@H]1CCO[C@H]2Cn3cc(C(=O)NCc4ccc(F)cc4F)c(=O)c(O)c3C(=O)N12</smiles>

Dolutegravir (11)

$\$ 6.1$ billion<smiles>O=C(NCc1c(F)cc(F)cc1F)c1cn2c(c(O)c1=O)C(=O)N1C(C2)O[C@H]2CC[C@@H]1CC2(Br)C(Br)(Br)Br</smiles>

$\$ 4.7$ billion

Figure 2. Top fluorine containing drugs by world sales in 2019.

\section{Teriflunomide (Aubagio ${ }^{\mathrm{TM}}$ )}

During the 1980s, an anti-inflammatory drug discovery program at Hoechst [5] led to the 
development of leflunomide (15, other names: HWA 486 [6], HR486 [5], SU101 [7]). Further studies showed that leflunomide (15) is quickly converted to teriflunomide 3, (also known as A77 1726 [5], SU0020 [7] or HMR1726 [8]) in vivo (in the intestinal mucosa and plasma) mainly by a nonenzymatic transformation as illustrated in Scheme 1. It is this metabolite that is responsible for the drugs bioactivity [5]. As a result, teriflunomide (3) was widely explored in place of leflunomide (15) in in vitro studies [6,9] and differences between the activities of $\mathbf{1 5}$ and $\mathbf{3}$ were rarely observed [10]. The main effect of teriflunomide (3) seems to be inhibition of dihydroorotate dehydrogenase [11] with an $\mathrm{IC}_{50}$ of $0.26 \mu \mathrm{M}$ [12]. According to QSAR, the $\mathrm{CF}_{3}$ group serves as an electronwithdrawing, hydrophobic group with low molar refractivity [13]. An X-ray crystal structure of the complex of teriflunomide with human dihydroorotate dehydrogenase demonstrated that the $\mathrm{CF}_{3}$ group occupies a small hydrophobic cavity of the enzyme [14].

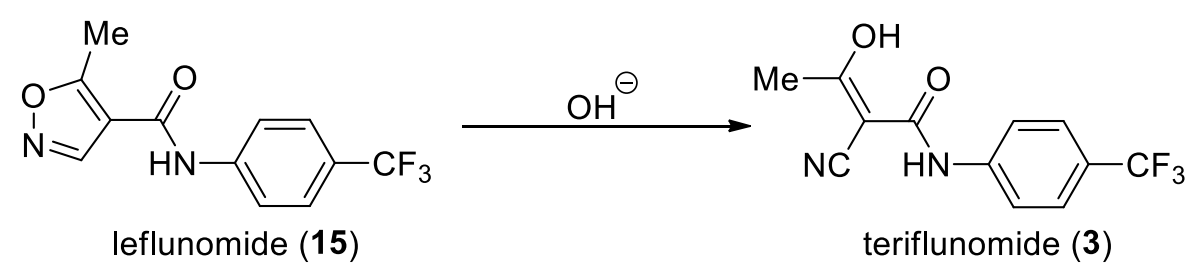

Scheme 1. The conversion of leflunomide (15) to teriflunomide (3).

Dihydroorotate dehydrogenase is an enzyme necessary for de novo pyrimidine synthesis $[5,11,15]$. As its name suggests, it transforms dihydroorotate into orotate, which is transformed further into uridine monophosphate $[5,15,16]$. Through the use of salvage pathways, most cells access sufficient amounts of pyrimidine nucleotides to function and divide. However, activated lymphocytes require much higher levels of pyrimidine nucleotides to progress from cell cycle stage G1 through the S phase, requiring de novo pyrimidine synthesis too. As a result, inhibition of dihydroorotate dehydrogenase arrests activated lymphocytes in the G1 phase, inhibiting antibody 
production in the case of B-cells and proliferation in the case of T-cells $[5,16]$. Other actions of teriflunomide have been reported too [9], but they are considered less important $[5,16]$.

The selective immunosuppressing effect of $\mathbf{1 5}$ and $\mathbf{3}$ made them highly suited for the treatment of autoimmune diseases. Clinical trials demonstrated that leflunomide (15) was safe except for an indication of teratogenic and embryotoxic effects in animal studies, efficacious, and tolerable, and it was approved by the FDA in 1998 for the treatment of rheumatoid arthritis $[5,16]$. Notably, immunomodulation was achieved without increasing the risk of opportunistic infections, a complication of many deoxynucleotide synthesis inhibitors [5]. It was also found that thanks to strong serum protein binding (99.5\%) and enterohepatic recirculation, metabolite 3 has a long halflife (15 days), but it can be quickly removed with cholestyramine [5,16]. Later, teriflunomide 3 was developed independently as a drug. Clinical trials showed that teriflunomide $\mathbf{3}$ is efficient in the treatment of relapsing remitting multiple sclerosis, where tolerability and safety were similar to those of leflunomide, and it was approved by the FDA in 2012 [17]. In Europe, the Committee for Medicinal Products for Human Use initially concluded that teriflunomide, as a metabolite of leflunomide, could not be considered a new active substance, but this opinion was later revised. It is noteworthy that with time, the teratogenic and embryotoxic effects of $\mathbf{1 5}$ and $\mathbf{3}$ appear less serious than originally thought [18].

Future therapeutic areas under investigation for leflunomide and teriflunomide involve treatment of cytomegalovirus and BK virus infections [19], multiple myeloma [19], breast cancer [20], and lupus nephritis [21].

Synthetic routes to access teriflunomide can be classified into two main groups. The first starts with cyanoacetylation of 4-trifluoromethylaniline, and the resulting product $\mathbf{1 6}$ is then acetylated at 
its active methylene group. Scheme 2 shows an example with DCC-mediated coupling followed by treatment with acetyl chloride and $\mathrm{NaH}$ [22]. Notably, the latter reagent combination was utilized in the first reported example of this synthetic pathway too [23]. Scheme 3 shows another example, where cyanoacetyl chloride is used, and isopropenyl acetate $/ \mathrm{NaOH}$ performs the second step [24]. Scheme 4 demonstrates that acetic anhydride and $\mathrm{NaOH}$ is also efficient in acetylating $\mathbf{1 6}$ [25].

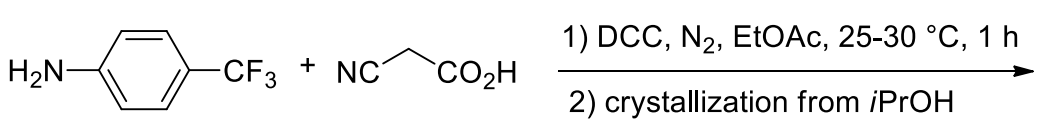<smiles>N#CCC(=O)Nc1ccc(C(F)(F)F)cc1OCCN</smiles>

1) $\mathrm{NaH}, \mathrm{THF}, \mathrm{N}_{2}, 0-5^{\circ} \mathrm{C}$

2) $\mathrm{AcCl},-5$ to $0^{\circ} \mathrm{C}, 90 \mathrm{~min}$

3) $\mathrm{AcOH}, 30 \mathrm{~min}$

4) crystallization from EtOAc

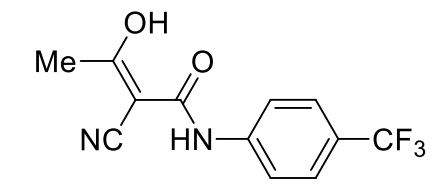

teriflunomide (3): $80 \%$ (99.6\% purity)

[recrystallization from EtOAc:

$60 \%(99.92 \%$ purity)]

Scheme 2. Synthesis of teriflunomide 3 via a DCC-mediated coupling.

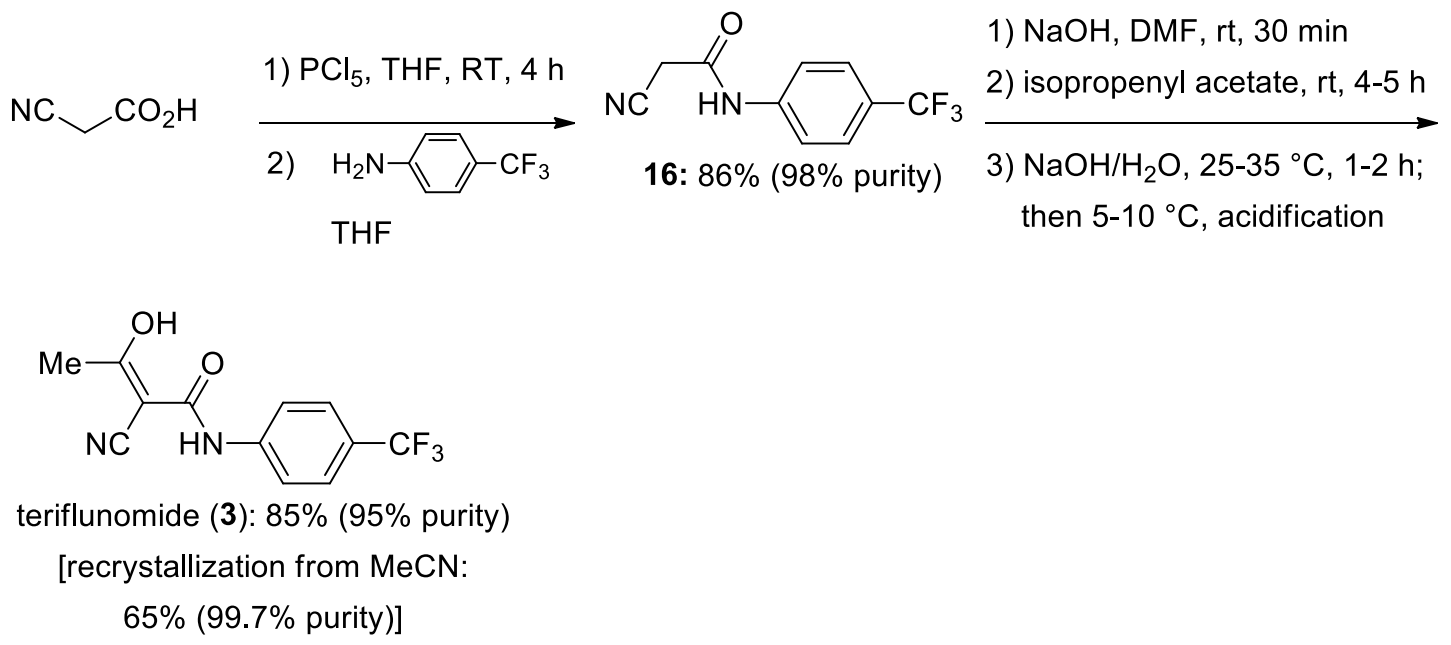

Scheme 3. Synthesis of teriflunomide 3 with cyanoacetyl chloride. 
<smiles>N#CCC(=O)Nc1ccc(C(F)(F)F)cc1</smiles>

16
1) $33 \% \mathrm{NaOH}(\mathrm{aq}), i \mathrm{BuCOMe}, 10-12{ }^{\circ} \mathrm{C}$

2) $\mathrm{Ac}_{2} \mathrm{O}$, at $7-12^{\circ} \mathrm{C}$

3) $\mathrm{H}_{2} \mathrm{O}, 3-5^{\circ} \mathrm{C}$

4) $\mathrm{HCl}, 3-5^{\circ} \mathrm{C}(\mathrm{pH}=1.1)$<smiles>CC(O)=C(C#N)C(=O)Nc1ccc(C(F)(F)F)cc1</smiles>
$91 \%(99 \%$ purity $)$

Scheme 4. Synthesis of teriflunomide 3 via acetylation of $\mathbf{1 6}$.

A related synthetic approach, shown in Scheme 5. reverses the order of these steps. That is, acetylation of ethyl cyanoacetate is accomplished initially, and then aniline is subjected to acylation by ethyl 2-cyanoacetoacetate 17 [26].

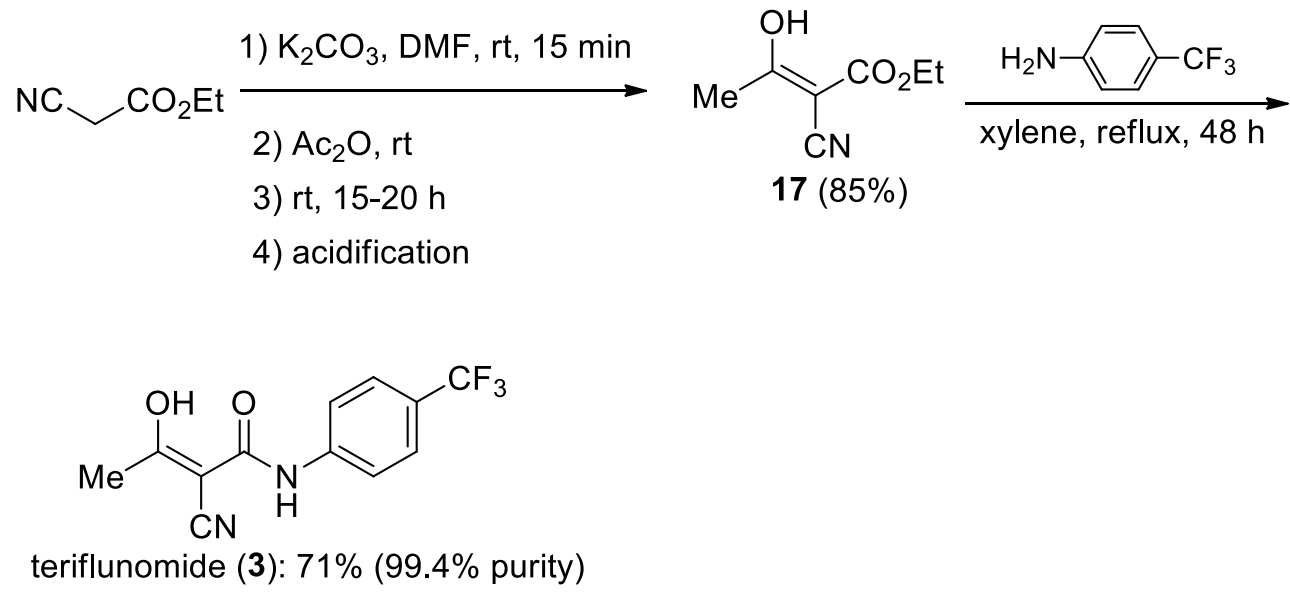

Scheme 5. Synthesis of teriflunomide 3 via 2-cyanoacetoacetylation.

The first reported synthesis of teriflunomide used an alternative strategy involving isomerization of leflunomide [27]. The necessary leflunomide is obtained through the reaction of 4(trifluoromethyl)aniline with an appropriate derivative of isoxazole carboxylic acid $\mathbf{1 8}[28,29]$, although other approaches are known [23]. Scheme 6 shows two examples. The first involves a traditional synthesis (acylation with acid chloride $\mathbf{1 9}$ and then isomerization of $\mathbf{1 5}$ with base) [28] and the second is an interesting mechanochemical synthesis (activation of $\mathbf{1 8}$ with 1,1'- 
carbonyldiimidazole, isomerization of $\mathbf{1 5}$ under acidic conditions) [29]. Note that the traditional synthesis used 4-(trifluoromethyl)aniline both as the nucleophile and the base, making the process less economic.

The sales for Teriflunomide (Aubagio ${ }^{\mathrm{TM}}$ ) in 2018, which is marketed by Sanofi-Aventis for the treatment of multiple sclerosis, were $\$ 1.67$ billion dollars.

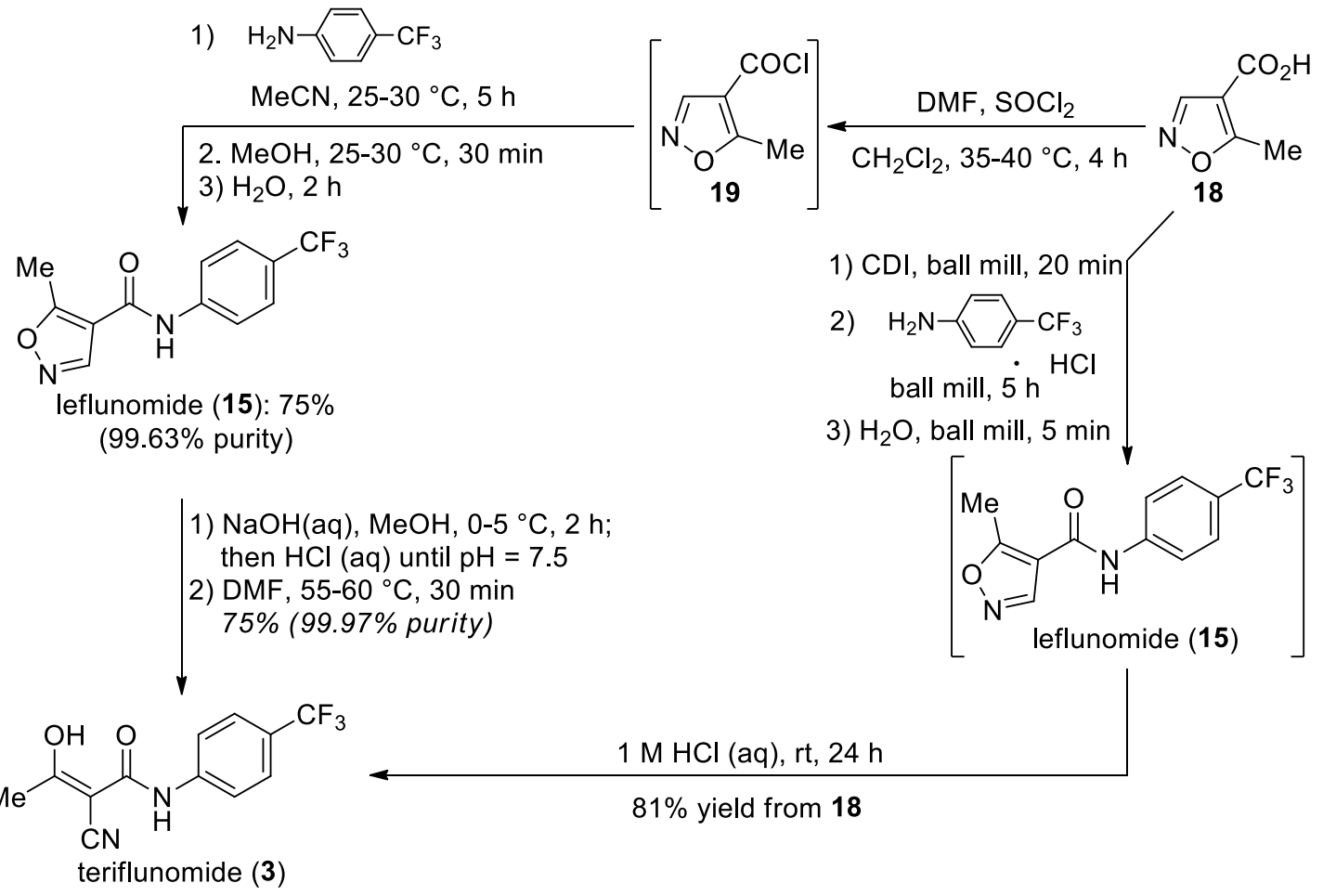

Scheme 6. Syntheses of teriflunomide through isomerization of leflunomide.

\section{Sitagliptin (Januvia' ${ }^{\mathrm{TM}}$, Glactiv $^{\mathrm{TM}}$, Tesavel ${ }^{\mathrm{TM}}$ )}

Sitagliptin (4) was developed by Merck as a dipeptidyl peptidase-4 (DPP4) inhibitor for the treatment of diabetes. Sitagliptin (4) (Figure 3) is a $\beta$-amino amide derivative containing a key trifluoromethylated triazolopyrazine moiety and 2,4,5-trifluorophenyl group, and notably it contains a stereogenic centre [30]. Structure-activity relationships (SAR) studies, varying substituents on the 
phenyl ring and the fused heterocycle found an obviously increased DPP4 inhibitory ability with the introduction of fluorine atoms at the settled positions, where an $\mathrm{IC}_{50}$ value of $18 \mathrm{nM}$ was observed for sitagliptin (4) [30]. Sitagliptin phosphate (Januvia ${ }^{\mathrm{TM}}$, Glactiv ${ }^{\mathrm{TM}}$, Tesavel $^{\mathrm{TM}}$ ) received approval by FDA in October 2006 for the treatment of Type II diabetes [31]. Sitagliptin phosphate (Januvia $^{\mathrm{TM}}$ ) earned receipts of $\$ 3.48$ billion which ranked in the 29 best-selling drug in 2019. Sitagliptin/metformin is also available as a single pill under the brand name Janumet ${ }^{\mathrm{TM}}$ in USA since 2007.<smiles>N[C@@H](CC(=O)N1CCn2c(nnc2C(F)(F)F)C1)Cc1cc(F)c(F)cc1F</smiles>
sitagliptin (4)

Figure 3. Structure of sitagliptin (4) used to treat Type II diabetes.

Merck reported a process for the preparation of sitagliptin (4) with triazolopyrazine $\mathbf{2 3}$ and $\beta$ amino acid 28 as the key intermediates (Scheme 7) [32]. This method was suitable for production on a multi-kilogram scale. The synthesis started with the arylation of hydrazine with 2chloropyrazine. The resultant 2-hydrazinylpyrazine (20) was treated by trifluoroacetic anhydride (TFAA) to generate bis-trifluorohydrazide 21, which underwent an intramolecular cyclization reaction in the presence of super phosphoric acid, affording the trifluoromethyl triazolopyrazine 22. Finally, Pd-catalyzed hydrogenation of triazolopyrazine $\mathbf{2 2}$ resulted in key intermediate $\mathbf{2 3}$ (Scheme 7). 


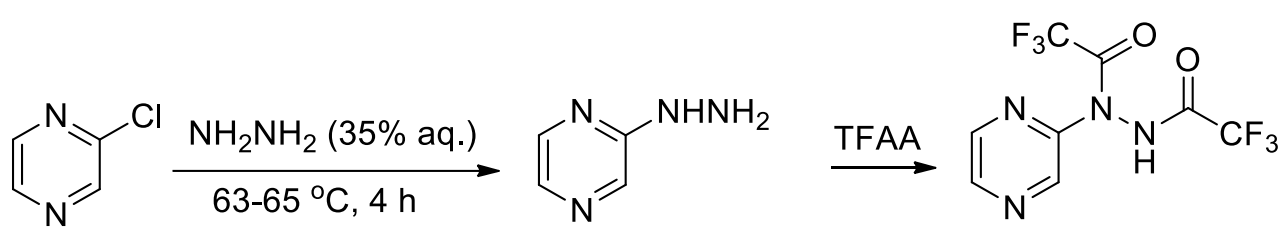

20

21

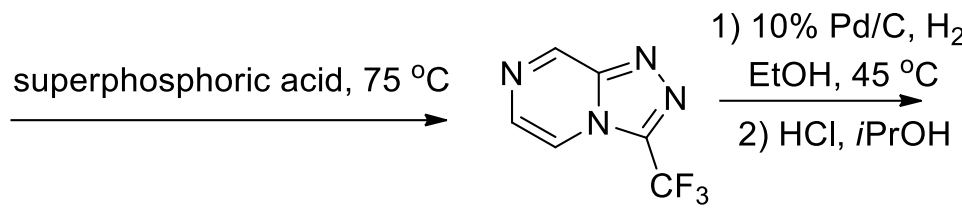

22<smiles>FC(F)(F)c1nnc2n1CCNC2</smiles>

23

Scheme 7. Synthesis of intermediate 23 for the preparation of sitagliptin (4).

The synthesis of $\beta$-amino acid $\mathbf{2 8}$ was shown in Scheme 8. An asymmetric Ru-catalyzed reduction of the carbonyl group on $\beta$-ketoester $\mathbf{2 4}$ is another illustration of the contribution of Noyori's asymmetric methodology to the development of pharmaceutical processes. This asymmetric reduction is followed by ester hydrolysis to generate intermediate $\mathbf{2 5}$. A coupling reaction between carboxylic acid 25 and $\mathrm{BnONH}_{2}$ in the presence of $\mathrm{EDC}-\mathrm{HCl}$ afforded hydroxamate 26, which was subjected to an intramolecular cyclization reaction to generate lactam 27. The treatment of lactam 27 with $\mathrm{HCl}$ and then a hydrolysis under basic conditions, provided the key intermediate $\mathbf{2 8}$. Triazole $\mathbf{2 3}$ was then coupled to amino acid $\mathbf{2 8}$ in the presence of EDC-HCl and $N$-methylmorpholine (NMM) to afforded intermediate $\mathbf{2 9}$, which was finally converted into sitagliptin (4) via a Pd-catalyzed hydrogenation. It should be noted that Soloshonok and co-workers applied their chiral Ni-complex approach to the synthesis of sitagliptin (4) [33]. 
<smiles>COC(=O)CC(=O)Cc1cc(F)c(F)cc1F</smiles>

24
1) (S)-BinapRuCl $2, \mathrm{HBr}$ (aq.) $\mathrm{H}_{2}, \mathrm{MeOH}, 80^{\circ} \mathrm{C}, 10 \mathrm{~h}$

2) $\mathrm{NaOH}, \mathrm{MeOH}, \mathrm{H}_{2} \mathrm{O}$<smiles>O=C(O)CC(O)Cc1cc(F)c(F)cc1F</smiles>

25<smiles>CCCc1cc(F)c(F)cc1CC1CC(=O)N1Cc1ccccc1</smiles>

1) $\mathrm{HCl}$ (aq.)

2) $\mathrm{KOH}, \mathrm{H}_{2} \mathrm{O}$<smiles>O=C(O)C[C@H](Cc1cc(F)c(F)cc1F)NOCc1ccccc1</smiles>

28<smiles>FC(F)(F)c1nnc2n1CCNC2</smiles>

23

EDC- $\mathrm{HCl}, \mathrm{NMM}, \mathrm{CH}_{3} \mathrm{CN}$

$0^{\circ} \mathrm{C}, 2 \mathrm{~h}$<smiles>O=C(CC(Cc1cc(F)c(F)cc1F)NO)N1CCn2c(nnc2C(F)(F)F)C1</smiles>

29

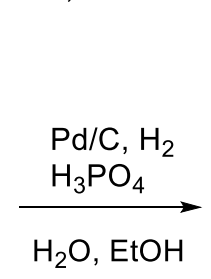

$\mathrm{H}_{2} \mathrm{O}, \mathrm{EtOH}$<smiles>CC(C)(C)c1nnc2n1CCN(C(=O)C[C@@H](N)Cc1cc(F)c(F)cc1F)C2</smiles>

Scheme 8. Synthesis of sitagliptin (4).

As a final note, we would like to point out that for the catalytic enantioselective reduction of

ketone $\mathbf{2 4}$ to alcohol 25, enantiomer self-disproportionation (SDE) tests [34] were not conducted despite an increasing awareness that fluorinated substrates usually perform well in such processes [35].

\section{Sofosbuvir}

Sofosbuvir (5), previously named GS-7977, was developed by Gilead Sciences as an antiviral agent, and approved by the FDA as Sovaldi ${ }^{\mathrm{TM}}[36]$ for the treatment of hepatitis C virus (HCV) infection in 2013. It fast become one of the best-selling drug on the market with sales exceeding $\$ 10$ billion 
in 2014. Sofosbuvir (5), is a pyrimidine-based nucleotide analogue featuring four contiguous stereogenic centers. It contains an L-alanine moiety, a chiral phosphoramidate unit, a 2'-fluorinated ribose ring and a uracil base (Figure 4) [37]. Sofosbuvir is also the active component in antiviral drug combinations. Harvoni ${ }^{\mathrm{TM}}$ contains ledipasvir and sofosbuvir as ingredients, a combination also developed by Gilead Sciences and approved by the FDA in 2014 for treating hepatitis C [38]. Harvoni $^{\mathrm{TM}}$ was the second best-selling drug on the market for the years 2015 and 2016 and collectively Sovaldi ${ }^{\mathrm{TM}}$ and Harvoni ${ }^{\mathrm{TM}}$ were grossing close to $£ 20$ billion per annum at this time. These drugs have become a victim of their own success in substantially suppressing the disease, and also as other products have entered the market, their impressive revenues have declined in the most recent years. Epclusa ${ }^{\mathrm{TM}}$, another combination drug, this time with sofosbuvir and velpatasvir was approved in June 2016, for the treatment of HCV regardless of HCV genotype or liver disease severity [39]. Epclusa ${ }^{\mathrm{TM}}$ rapidly reached blockbuster status, earning \$1.9 billion in 2019.

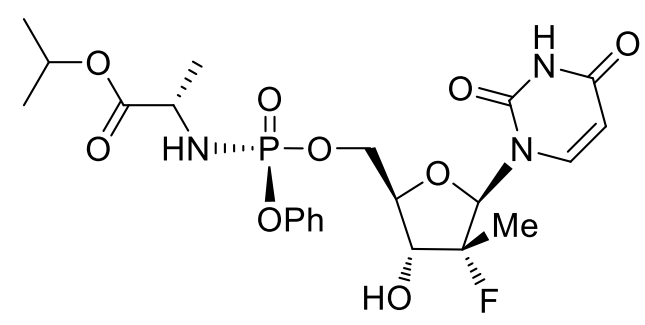

Sofosbuvir (5)

Figure 4. Sofosbuvir (5) used to treat hepatitis $\mathrm{C}$ often also in combination therapies.

The original synthesis of sofosbuvir (5) started from (R)-4-isopropyloxazolidin-2-one (30) with (3R,4R,5R)-3-fluoro-4-hydroxy-5-(hydroxymethyl)-3-methyldihydrofuran-2(3H)-one (34) as the key intermediate (Schemes 9 and 10). Acylation of (R)-4-isopropyloxazolidin-2-one (30) with 2- 
fluoropropanoyl chloride afforded amide 31, which was subjected to a Ti-promoted aldol reaction with acrolein. An intriguing intramolecular cyclization of the aldol product $\mathbf{3 2}$ with NBS gave lactone 33, which was converted to alcohol $\mathbf{3 4}$ after treatment with $\mathrm{KOH}$ [40].
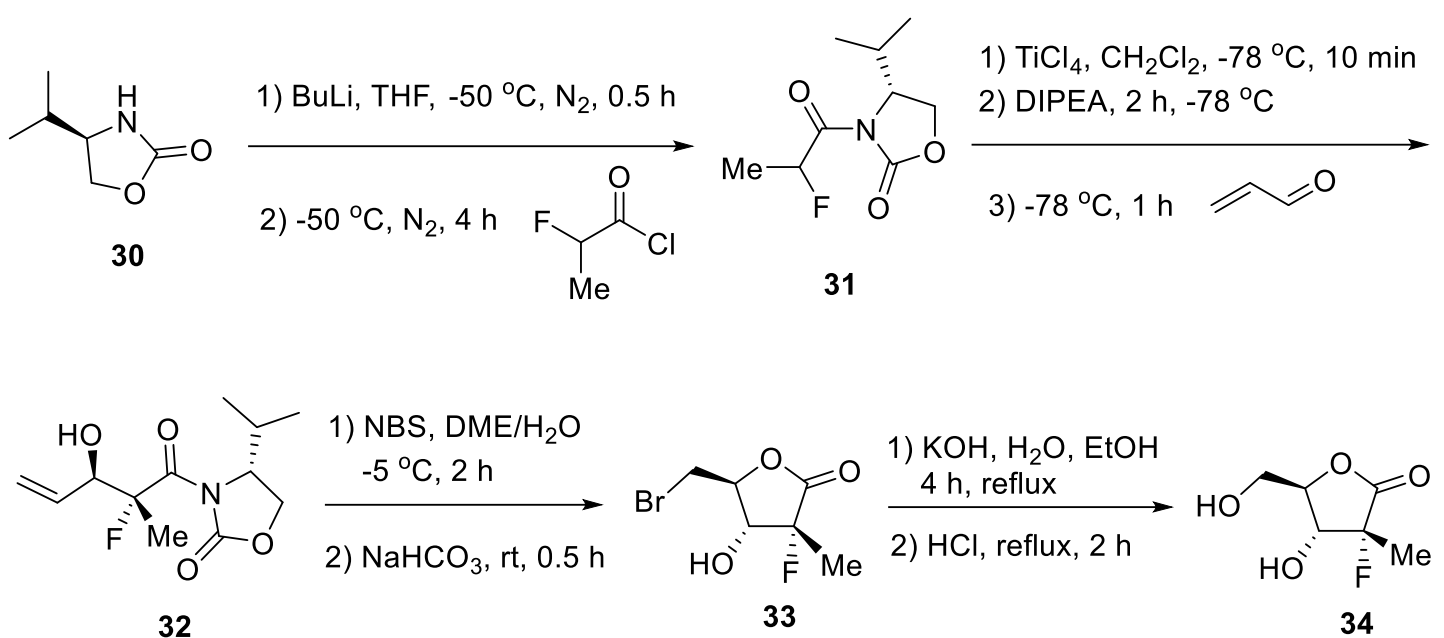

Scheme 9. Synthesis of the key intermediate 34 in sofosbuvir synthesis.

With the central ribose moiety substantially assembled, the remaining peripheral aspects of sofosbuvir 5 were introduced as illustrated in Scheme 10. Silyl ether protection of hydroxymethyl group of lactone $\mathbf{3 4}$ was followed by the 3'-O-benzyl-protection to generate intermediate 35 . This lactone was then reduced and acetylated at the anomeric position in a stereospecific manner, affording lactol 36 now with four contiguous stereogenic centers. The introduction of the nucleotide base was initiated with a $\mathrm{SnCl}_{4}$-promoted reaction between lactol 36 and $\mathrm{N}-(2-$ ((trimethylsilyl)oxy)pyrimidin-4-yl)benzamide to give 37 and the hydrolysis completed the introduction of the uridine moiety. The pro-drug arm at the 5'-O ribose oxygen was introduced after TBS ether removal and followed by reaction with (2S)-isopropyl 2((chloro(phenoxy)phosphoryl)amino)propanoate (39) to generate phosphoramidate 40, a process 
that occurs with high diastereoselectivity (92:8 dr). Finally, Pd-catalyzed deprotection released the desired sofosbuvir (5) [41].
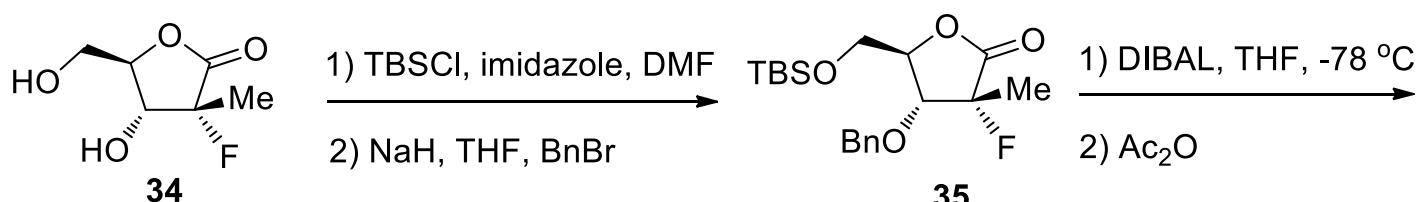<smiles>COc1nccc(NC(=O)c2ccccc2)n1</smiles>

36<smiles>CC1(F)[C@H](OCc2ccccc2)[C@@H](CO)O[C@H]1n1ccc(=O)[nH]c1=O</smiles>

38

1) $i-\mathrm{PrMgCl}, \mathrm{LiCl}$, THF

2)

$\mathrm{Ol}^{-} \mathrm{P}-\mathrm{NH} 39$
37

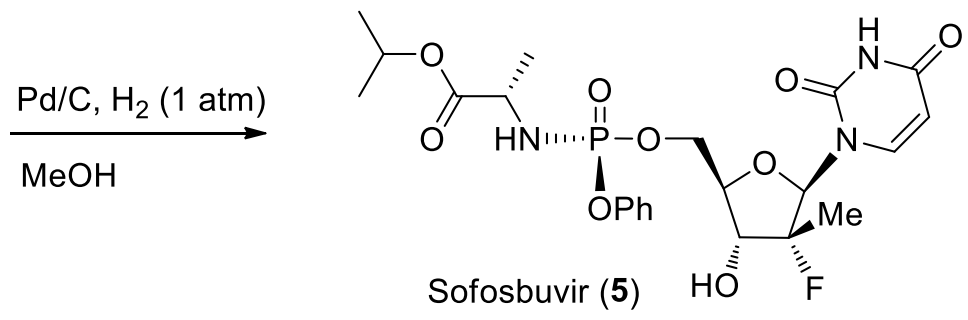

Scheme 10. Synthesis of sofosbuvir (5).

\section{Paliperidone palmitate (Invega ${ }^{\mathrm{TM}}$ Sustenna $^{\mathrm{TM}}$ )}

The history of paliperidone palmitate has its origins with risperidone (41), an atypical antipsychotic, a drug which was launched commercially in 1994 [42]. Risperidone (41) is highly potent but its therapeutic range is not so wide. Together with the extrapyramidal side effects associated with 
risperidone overdose, this generated interest in a sustained or delayed release formulation for risperidone and related compounds [43]. In theory, such formulations decrease the risk of adverse side effects through reducing fluctuations in plasma concentrations [44]. 9-Hydroxyrisperidone or paliperidone $( \pm)-42$, the main metabolite of risperidone (41), emerged as more promising for such purposes, because it has a similar potency and pharmacological profile to its parent, however its elimination half-life is longer ( $20 \mathrm{~h}$ vs. $2-4 \mathrm{~h})$ than risperidone $[42,43]$. The use of paliperidone 42 also negates the effects of genetic polymorphism on risperidone metabolism [43]. The hepatic metabolism of paliperidone is not significant as it is excreted mostly unchanged through the kidney, making clinically relevant metabolic drug-drug interactions unlikely [44]. Interestingly, the pure $R$ and $S$ enantiomers of paliperidone $\mathbf{4 2}$ have qualitatively and quantitatively similar in vitro pharmacological activity [44]. The above efforts first led to FDA approval of racemic paliperidone ( \pm )-42 in 2006 as an extended-release formulation using an osmotically controlled release oral delivery system. This enabled once-daily administration without initial dose titration $[42,44]$. Meanwhile, paliperidone palmitate ( \pm )-6 was identified as a promising candidate for intramuscular depot formation [43]. Paliperidone ( \pm )-42 becomes available in the body only after intramuscular hydrolysis of dissolved paliperidone palmitate $( \pm)-6$, but $( \pm)-6$ dissolves only slowly at the injection site thanks to its extremely low water solubility, a property that facilitates once-monthly dosing only [45]. Surprisingly, aqueous suspensions of $( \pm)-6$ performed better than more traditional oil suspensions [43]. After successful clinical trials, the FDA approved Invega ${ }^{\circledR}$ Sustenna ${ }^{\circledR}$ (an aqueous suspension of paliperidone palmitate for intramuscular injection) for the acute and maintenance treatment of schizophrenia in adults in 2009 [45]. Subsequent formulations have been licensed as Trinza (2015) and Trevicta (2016). All of the above molecules (Scheme 11) were developed by 
Janssen Pharmaceutica, a subsidiary of Johnson \& Johnson and collectively these drugs are grossing over \$2 billion in sales in 2019 .

Both 41 and $( \pm)-42$ exert their antipsychotic activity via antagonism of serotonin $5-\mathrm{HT}_{2 \mathrm{~A}}$ and dopamine $\mathrm{D}_{2}$ receptors [44].<smiles>Cc1nc2n(c(=O)c1CCN1CCC(c3noc4cc(F)ccc34)CC1)CCCC2</smiles>
paliperidone palmitate $[( \pm)-6]: \mathrm{R}=\mathrm{CO}\left(\mathrm{CH}_{2}\right)_{14} \mathrm{CH}_{3}$

Scheme 11. Structures of the antipsychotic drugs risperidone (41), paliperidone $( \pm)-\mathbf{4 2}$, and paliperidone palmitate $( \pm)-6$.

Paliperidone palmitate is obtained mostly via palmitoylation of paliperidone. The initial synthesis of paliperidone used 3-benzyloxy-2-aminopyridine which, in reaction with lactone $\mathbf{4 3}$ in the presence of $\mathrm{POCl}_{3}$, afforded heterocycle 44. Catalytic hydrogenation of $\mathbf{4 4}$ led to $( \pm)$ alcohol $\mathbf{4 5}$ which is then treated without purification with piperidine derivative 46 to generate $( \pm)-42$ as the final product as illustrated in Scheme $12[43,46]$. 


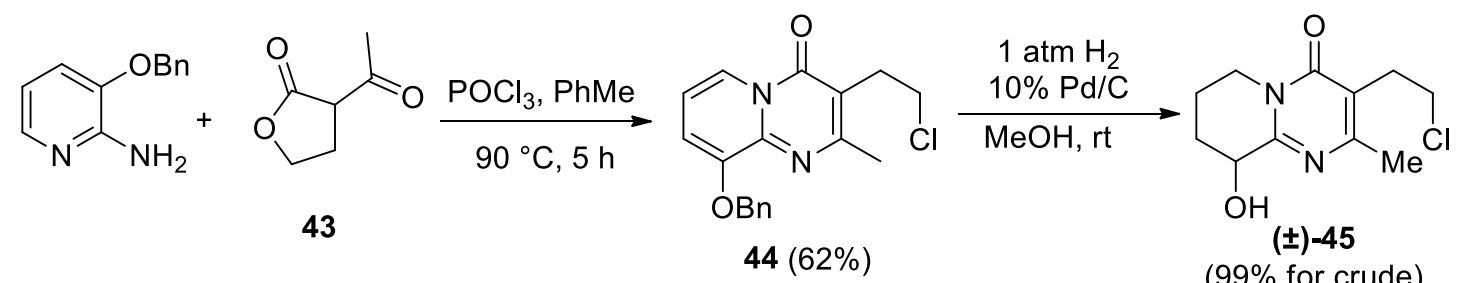<smiles>COc1nc2n(c(=O)c1CCN1CCC(c3noc4cc(F)ccc34)CC1)CCCC2O</smiles>

Scheme 12. Early paliperidone ( \pm )-42 synthesis.

This synthesis suffered from various problems. The final step required chromatographic separation and the purities of products were not reported. This resulted in considerable interest in achieving improved syntheses [47-60] and led to the identification of typical impurities (risperidone 41, ketone 47, phenol ( \pm )-48, $N$-oxide $( \pm)-49)$ as well as competing side reactions (e.g. formation of dechlorinated ( \pm )-50 during hydrogenation). Scheme 13 shows these impurities (except compound 41) and byproducts. It was found that performing the hydrogenation of $\mathbf{4 2}$ under acidic conditions suppressed dechlorination [51,56]. Formation of the ketonic impurity $\mathbf{4 7}$ from ( \pm )-42 is enhanced in the presence of metal ions (especially iron and zinc). Therefore, active charcoal used in the crystallization steps must contain less than $200 \mathrm{ppm}$ of individual metal cations and a neutral or alkaline $\mathrm{pH}$ value when dispersed in water [57]. After formation, impurity 47 can be reduced to paliperidone $[53,55,58]$ or removed via basic treatment [60]. The latter process also eliminated phenol byproduct 48 [60]. $N$-Oxide $( \pm)-49$ is formed from paliperidone under oxidative conditions and even THF with $>0.015 \%$ peroxide content is sufficient to induce its formation [60]. After heterocycle $\mathbf{4 4}$ formation and then hydrogenation, byproduct $( \pm)-50$ and impurity $\mathbf{5 1}$ formed, whose 
removal during purification of $( \pm)-45$ reduces the content in the final product $( \pm)-42[60]$.

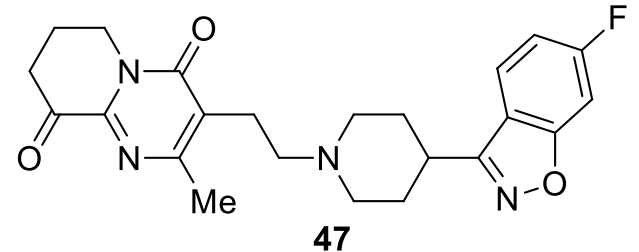

47<smiles>Cc1nc2n(c(=O)c1CC[N+]1([O-])CCC(c3noc4cc(F)ccc34)CC1)CCCC2O</smiles>

$( \pm)-49$

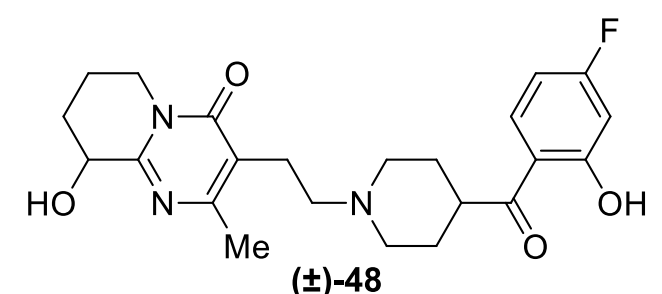<smiles>CCc1c(C)nc2n(c1=O)CCCC2O</smiles>

(士)-50<smiles>Cc1nc2n(c(=O)c1CCCl)CCCC2</smiles>

51

Scheme 13. Structures of impurities during paliperidone synthesis. Hydrogenation byproduct $( \pm)-$

50 and impurity 51 are present in intermediate ( \pm )-45.

The best yields and purities for the different steps are found in different publications. Following the original synthetic approach, the formation of $\mathbf{4 4}$ was the most effectively achieved as described by Dolitzky [47]. A high-yielding (98\%) hydrogenation protocol of $\mathbf{4 4}$ was reported by Kankan et al., [51], but the purity of the resulting ( \pm )-45 was only $90 \%$. A one-pot transformation of 3(benzyloxy)pyridin-2-amine into ( \pm )-45, as reported by Solanki et al., [60], was less productive but yielded a product of $99.5 \%$ purity. Changing the synthetic pathway such as the transformation of $\mathbf{5 2}$ into ( \pm )-45, without benzylation/debenzylation proved even more advantageous [58] as summarized in Scheme 14. 
<smiles>Nc1ncccc1OCc1ccccc1Br</smiles>

1) $43, p \mathrm{TsOH}, \mathrm{PhMe}$, reflux, $30 \mathrm{~h}$

2) $\mathrm{POCl}_{3}$, diglyme, $90^{\circ} \mathrm{C}, 4.5 \mathrm{~h}$

3) $25 \% \mathrm{NH}_{3}$ (aq) until $\mathrm{pH}=7$

Ref. [47], $85 \%$ overall yield ( $299.7 \%$ purity)

1) $\mathrm{POCl}_{3}, \mathrm{PhMe}$

2) $43,68-70{ }^{\circ} \mathrm{C}, 30-35 \mathrm{~h}$

3) $1 \mathrm{~atm} \mathrm{H}_{2}, 10 \% \mathrm{Pd} / \mathrm{C}$

4. crystallization from $\mathrm{MeOH}$<smiles>CCCCOc1cccn2c(=O)c(CCCl)c([N+](=O)[O-])nc12</smiles>

$\mathrm{H}_{2}, 10 \% \mathrm{Pd} / \mathrm{C}$

AcOH, EtOAc, $25-30{ }^{\circ} \mathrm{C}, 15 \mathrm{~h}$

Ref. [51], 98\% yield

Ref. [60], $49 \%$ overall yield (99.5\% purity)<smiles>Cc1nc2n(c(=O)c1CCCl)CCCC2O</smiles>

$( \pm)-45$

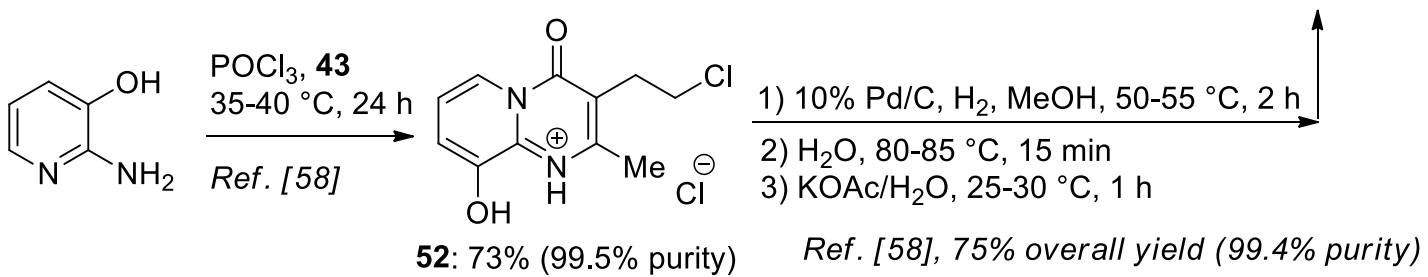

Scheme 14. Improved synthetic approaches towards intermediate $( \pm)-\mathbf{4 5}$ required for paliperidone synthesis.

Scheme 15 shows three methods which were optimized for the efficient preparation of paliperidone $( \pm)-42$ from $( \pm)-45$ and the hydrochloric salt of $\mathbf{4 6}$, generating the product in good yields and high purity. The earliest method used the relatively expensive $i \operatorname{Pr}_{2} \mathrm{NEt}$ as a base, and with two additives ( $\mathrm{NaI}$ and $n \mathrm{Bu} 4 \mathrm{NBr}$ ), and the work up required the precipitation of paliperidone tartrate to achieve the desired yield and purity [58]. By contrast, the second method had a more straightforward work up using $\mathrm{K}_{2} \mathrm{HPO}_{4}$ as the base and $\mathrm{KI}$ [59]. Finally the most suitable approach for reliability on a multikilogram scale used $i \operatorname{Pr}_{2} \mathrm{NH}$ as the base and DBU as an additive, and this could be accomplished with a relatively straightforward work up protocol [60]. 


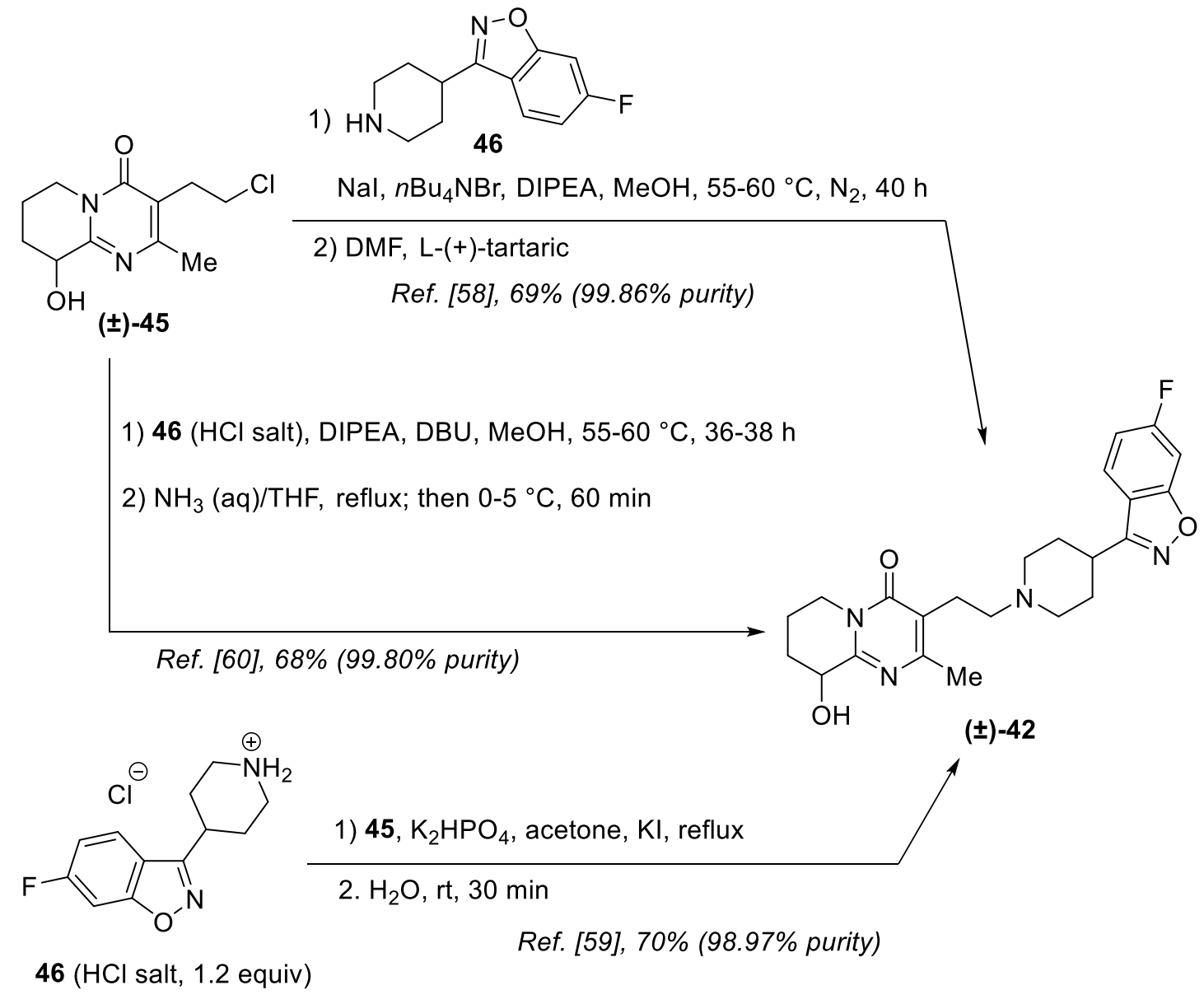

Scheme 15. Various methods for the final step in paliperidone $\mathbf{4 2}$ synthesis.

Riva et al. reported a fundamentally different paliperidone $\mathbf{4 2}$ synthesis. This involved selective deprotonation of risperidone 41, followed by reaction with molecular oxygen $\left(\mathrm{O}_{2}\right)$, followed by reduction of the formed hydroperoxide (Scheme 16) [61].
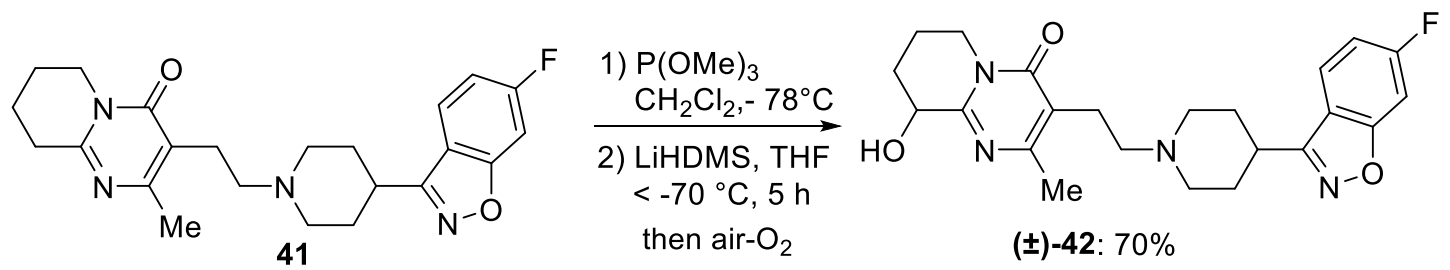

(士)-42: $70 \%$

Scheme 16. Synthesis of paliperidone 42 via selective hydroxylation of risperidone.

Paliperidone palmitate $( \pm)-\mathbf{6}$ can be prepared easily from paliperidone $( \pm)-\mathbf{4 2}$ through 
palmitoylation. Palmitic acid and DCC [43,46] or palmitoyl anhydride [62] provide good results (Scheme 17), while direct acylation with palmitoyl chloride proved inferior [63]. The 9-Oacetylated derivative of paliperidone can be purified more easily than its parent compound [64] suggesting that a final purification of paliperidone palmitate may offer an approach but utilizing more readily available albeit less pure ( \pm )-42, as illustrated in Scheme 17.<smiles>Cc1nc2n(c(=O)c1CCN1CCC(c3noc4cc(F)ccc34)CC1)CCCC2O</smiles>

\section{$( \pm)-42$}

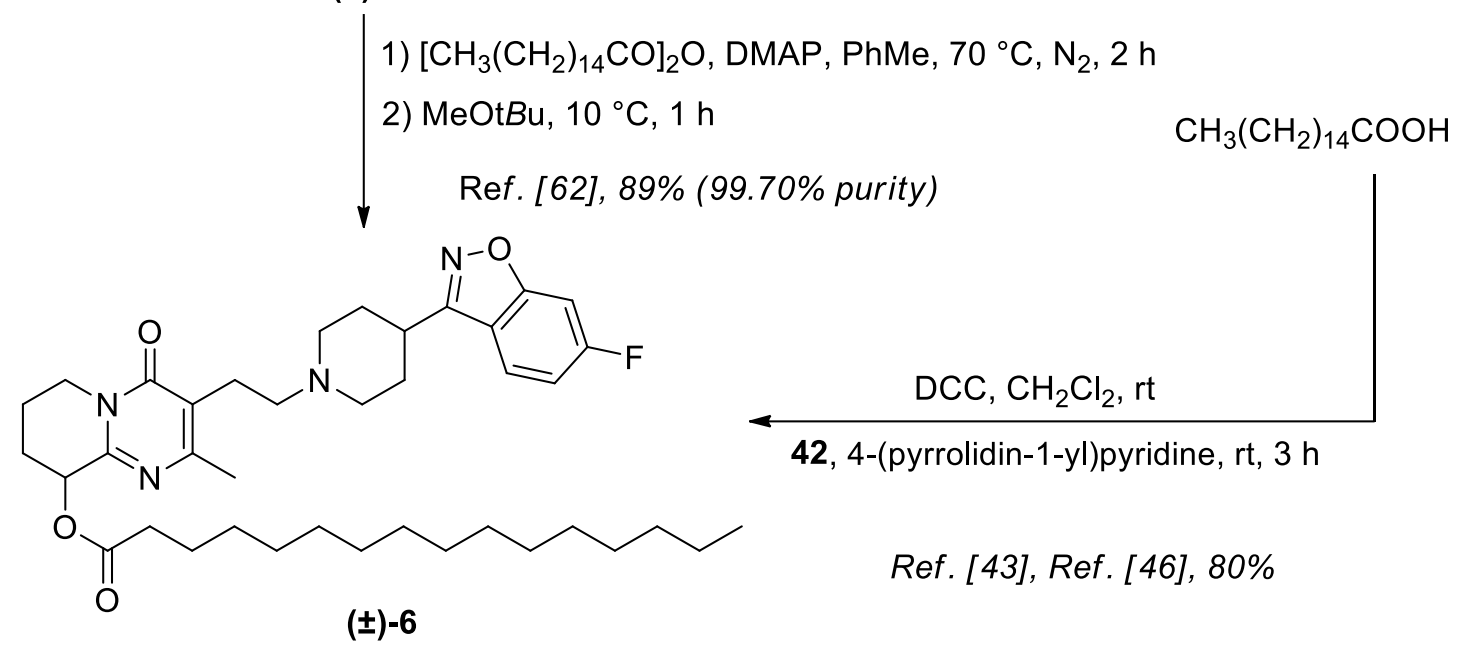

Scheme 17. Palmitoylation of paliperidone to generate ( \pm )-6.

Alternatively, there is patent where intermediate ( \pm )-45 was subjected directly to palmitoylation, and where substitution with amine 46 ( $\mathrm{HCl}$ salt) constitutes the final step to paliperidone palmitate $( \pm)-6$, however the purities and yields of products are not given in any detail [65].

\section{Glecaprevir/pibrentasvir (Mavyret ${ }^{\mathrm{TM}}$ )}


Glecaprevir (7), previously named ABT-493, was developed by AbbVie as a next-generation, orally administered drug for the treatment of hepatitis $\mathrm{C}$ virus $(\mathrm{HCV})$ infection. It is a $\mathrm{HCV} \mathrm{NS} 3 / 4 \mathrm{~A}$ protease inhibitor (PI). The compound is extremely active with in vitro $\mathrm{IC}_{50}$ values in the low nanomolar range across various HCV genotypes 1-6 [66]. Glecaprevir (7) is a stereochemically complex macrocyclic compound featuring several amino acid moieties, including tert-leucine, proline and 1-aminocyclopropanecarboxylic acid. In 2017, glecaprevir 7 and the HCV NS5A inhibitor pibrentasvir (ABT-530) 8 were approved under the trade name Maviret ${ }^{\mathrm{TM}}$ in USA and EU as a single tablet fixed-dose combination treatment of chronic HCV genotypes 1, 2, 3, 4, 5 or 6 [66]. Mavyret $^{\mathrm{TM}}$ (Glecaprevir/pibrentasvir) earned a total \$2.89 billion sales in 2019. Both glecaprevir (7) and pibrentasvir (8) have a high degree of fluorination with four and five fluorine atoms respectively (Figure 5) [67,68].

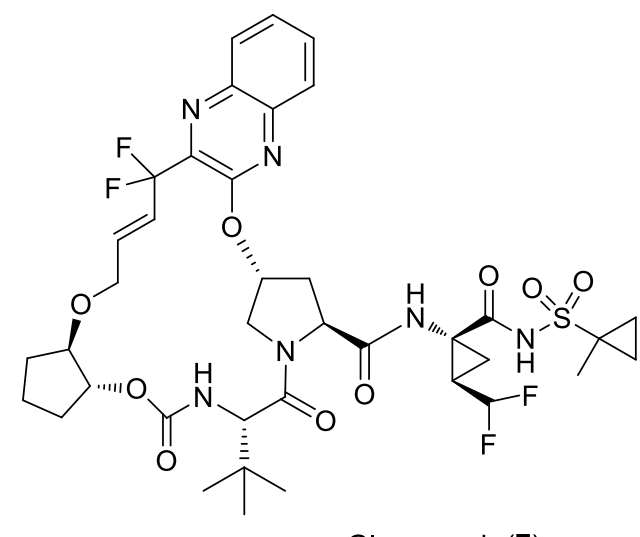

Glecaprevir (7)<smiles>COC(=O)N[C@H](C(=O)N1CCC[C@H]1c1nc2cc(C3CC[C@@H](c4cc5nc([C@@H]6CCCN6C(=O)[C@@H](NC(=O)OC)C(C)OC)[nH]c5cc4F)N3c3cc(F)c(N4CCC(c5ccc(F)cc5)CC4)c(F)c3)c(F)cc2[nH]1)C(C)C</smiles>

Mavyret $^{\mathrm{TM}}$ (Glecaprevir/pibrentasvir)

Figure 5. Structures of the HVC drugs glecaprevir (7) and pibrentasvir (8).

Cink and co-authors from AbbVie Inc. successfully developed a process for the preparation of 
glecaprevir (7) via ring-closing metathesis reaction, which was reported to produce a batch of $41 \mathrm{~kg}$ of glecaprevir [69]. Mono-Boc-protected amino ester $\mathbf{5 3}$ was progressed to the di-Boc intermediate 54, and then the alkene moiety was oxidized to afford aldehyde $\mathbf{5 5}$ as a means to access the difluoromethyl group. The fluorination used DAST and the resultant difluoromethyl ester $\mathbf{5 6}$ was hydrolysed to the corresponding carboxylic acid $\mathbf{5 7}$ and was coupled with 1-methylcyclopropane1-sulfonamide to give sulfonamide $\mathbf{5 9}$ as a key intermediate (Scheme 18).

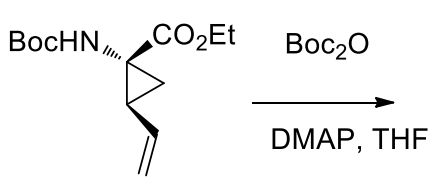

53

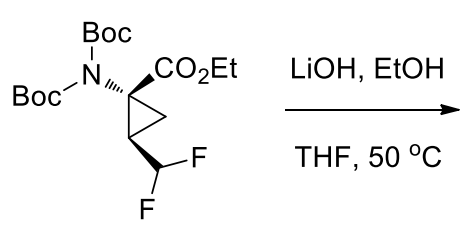

56

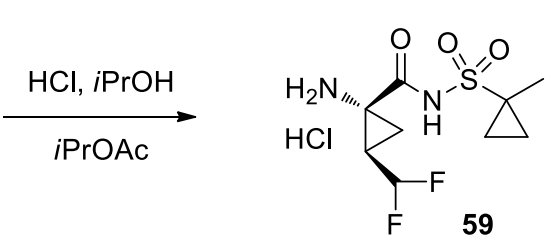

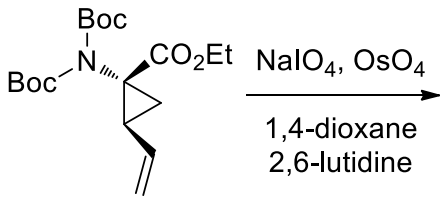

54

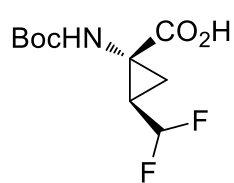

57<smiles>CC(C)(C)OC(=O)N(C(=O)OC(C)(C)C)C1(C(=O)O)CC1C(=O)OCc1ccccc1</smiles>

55
1) DAST, 2,6-lutidine $\mathrm{CH}_{2} \mathrm{Cl}_{2}, 20^{\circ} \mathrm{C}$

2) $\mathrm{K}_{2} \mathrm{HPO}_{4}$ (aq.) heptanes

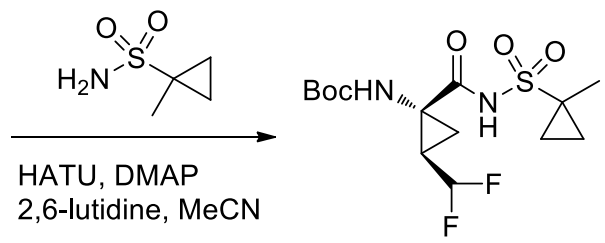

58

Scheme 18. Synthesis of sulfonamide $\mathbf{5 9}$ used in the synthesis of glecaprevir 7.

The terminal difluoroallyl olefin $\mathbf{6 5}$ is a precursor for the key metathesis reaction and was prepared as illustrated in Scheme 19. Accordingly $\alpha$-hydroxyl ester $\mathbf{6 0}$ was oxidised to $\alpha$-keto ester 61 and was condensed with diaminobenzene to afford the quinoxaline 62, which was then progressed to chloro quinoxaline 63. An $\mathrm{S}_{\mathrm{N}} \mathrm{Ar}$ substitution reaction with Boc-protected hydroxyproline, as a free carboxylic acid, then afforded ether $\mathbf{6 4}$, and finally esterification with 
concomitant deprotection gave ester $\mathbf{6 5}$ as an amine hydrochloride.<smiles>C=CC(F)(F)C(O)C(=O)OCC</smiles>

60

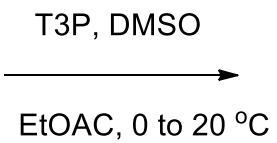

EtOAC, 0 to $20^{\circ} \mathrm{C}$<smiles>C=CC(F)(F)C(=O)C(=O)OCC</smiles>

61

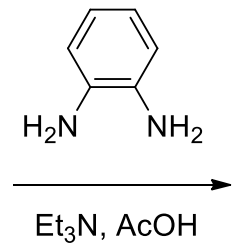

$\mathrm{Et}_{3} \mathrm{~N}, \mathrm{AcOH}$<smiles>C=CC(F)(F)c1nc2ccccc2nc1O</smiles>

62

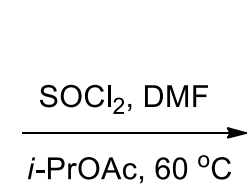<smiles>C=CC(F)(F)c1nc2ccccc2nc1O[C@H]1CN[C@H](C(=O)OC)C1</smiles>

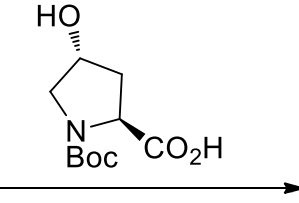

$t$-BuONa, DMF, $0{ }^{\circ} \mathrm{C}$<smiles>C=CC(F)(F)c1nc2ccccc2nc1O[C@H]1CC(C(=O)O)N(C(=O)OC(C)(C)C)C1</smiles>

65

Scheme 19. Synthesis of intermediate $\mathbf{6 5}$ used in the synthesis of glecaprevir 7 .

Another key building block $\mathbf{6 8}$ for the metathesis reaction was required as a single enantiomer and this was achieved by an enzymatic resolution of racemic acetate $\mathbf{6 6}$. This involved the selective hydrolysis of acetate 66 with Novozym 435 to generate an intermediate alcohol (not shown) by kinetic resolution. Workup involved treatment with triphosgene to afford chloroformate $\mathbf{6 7}$ as a single diastereoisomer, and this intermediate was then coupled with tert-leucine and treated isolated as its dicyclohexylamine salt 68 . The free carboxylic acid moiety of $\mathbf{6 8}$ was now coupled with amine 65 to produce 69 containing two remote terminal olefins and primed for a RCM reaction. This was achieved using Zhan 1B as a catalyst to generate macrocyclic ester 70. The ester moiety was hydrolysed to generate carboxylic acid 71, and which was coupled with sulfonamide $\mathbf{5 9}$ to furnish glecaprevir (7) (Scheme 20). 


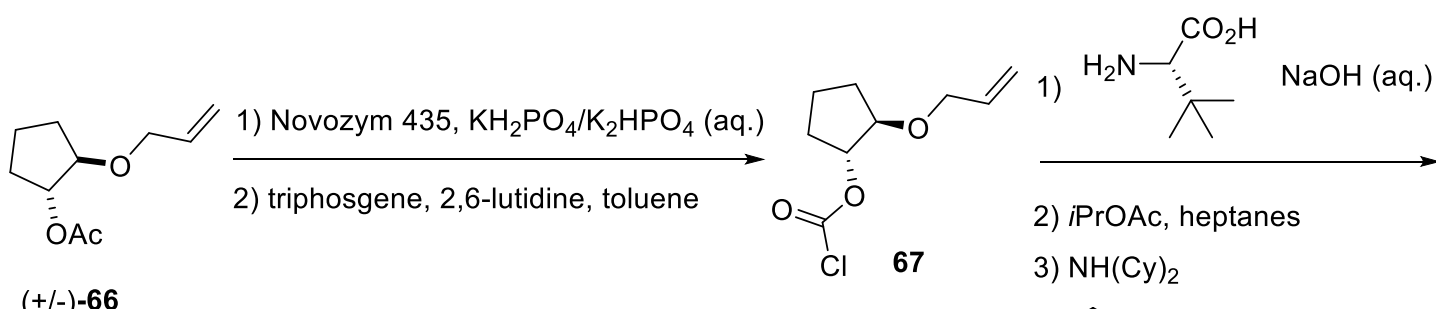

$(+/-)-66$

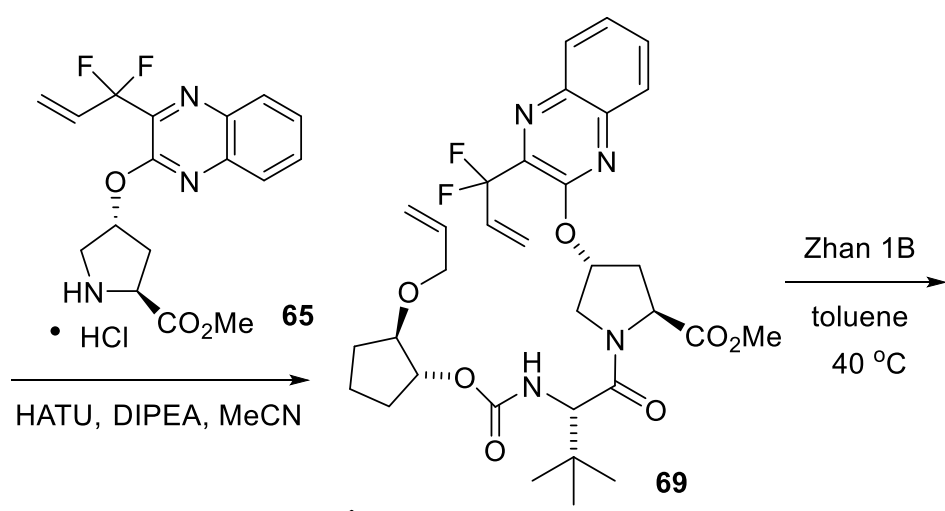<smiles>CC(=O)O[C@H]1C[C@@H](Oc2nc3ccccc3nc2C(F)(F)/C=C/CO[C@H]2CCC[C@@H]2OC(=O)NC(F)F)CN1C(=O)[C@@H](NO[NH3+])C(C)(C)C</smiles>

70

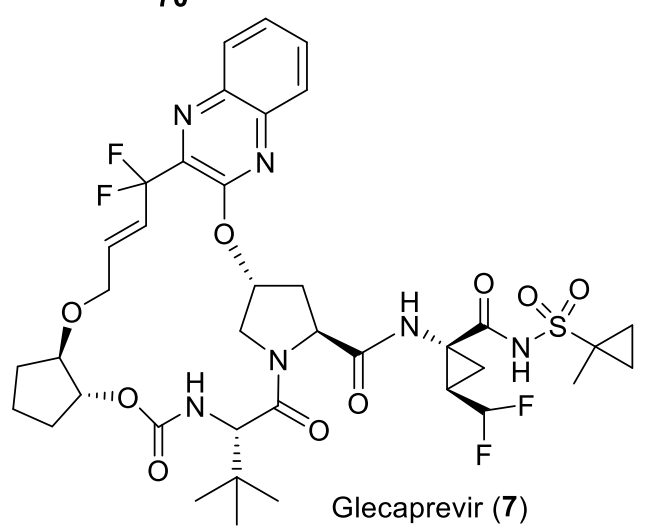

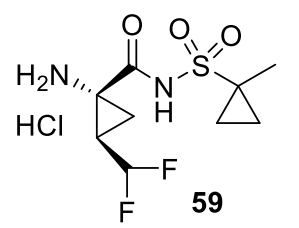

1) EDAC, HOPO, MeCN, TEA

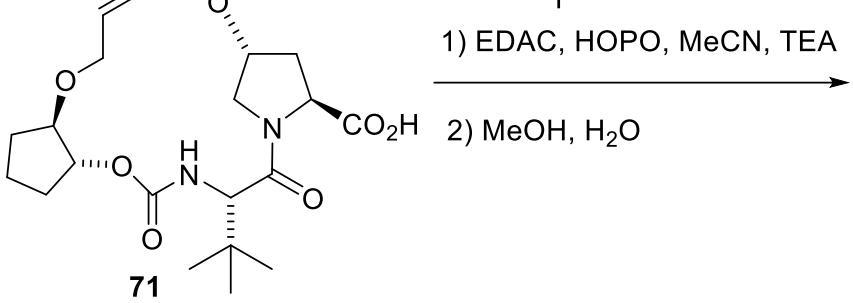

Scheme 20. The final steps for the synthesis of glecaprevir (7).

Alternative approaches for the preparation of $(1 R, 2 S)$-1-amino-2-vinylcyclopropanecarboxylic acid 57 by alkylation/cyclization of chiral nucleophilic glycine equivalents have also been developed [70]. 
The synthesis of glecaprevir 7 illustrates how the assembly of complex structures with high degrees of stereochemistry and peppered with fluorines, are no longer the daunting tasks that they used to be as synthesis methodology has developed.

\section{Elvitegravir}

Elvitegravir (9) is an anti-retroviral used in the treatment of HIV. It was developed by Japan Tobacco, and licensed for worldwide production by Gilead Sciences (Figure 6) [71]. Elvitegravir was branded as Vitekta for single medication, and received clinical approval from the FDA in 2014 [72]. The drug was recommended to be taken in combination with other anti-retrovirals including an HIV protease inhibitor and a pharmacokinetic booster, usually cobicistat or ritonavir. Such boosters inhibit metabolizing cytochrome P450 enzymes, and this combination offset elvitegravir metabolism improving bioavailability and half-life [73]. With a booster, elvitegravir can be taken once daily [74], however, the drug was voluntarily withdrawn as a single medication in 2017 and became available in Genvoya, a combination treatment. Genvoya is a four-drug combination that contains elvitegravir, cobicistat (a pharmacokinetic booster), emtricitabine and tenofovir disoproxil fumarate (nucleoside/nucleotide reverse transcriptase inhibitors). It was the $12^{\text {th }}$ most successful drug commercially in the United States in 2018 , clearing sales of $\$ 3.63$ billion.<smiles>COc1cc2c(cc1Cc1cccc(Cl)c1F)c(=O)c(C(=O)O)cn2C(CO)C(C)C(C)C</smiles>

Figure 6. Structure of elvitegravir 9. 
Elvitegravir is an integrase strand transfer inhibitor (INSTI), which acts on HIV-1 integrase (IN) [75] and accordingly it suppresses integration of HIV-2 coded DNA into the host's genome [76]. Integration takes place in three sequential steps, terminal 3'-DNA processing, DNA strand transfer and gap repair [77]. The IN enzyme catalyzes the first two of these steps [78]. The 3'-DNA processing step involves the hydrolysis of the two terminal 3'-nucleotides of the reverse transcribed HIV complementary DNA. The modified HIV coded DNA is then integrated into the host chromosome in the strand transfer step. Gap repair then completes the process, annealing the guest DNA in the hosts chromosome. The HIV-1 IN enzyme contains three carboxylic acid residues (D64, D116 and E152) in its active site, which are involved in catalyzing the strand transfer reaction. These residues secure two $\mathrm{Mg}^{2+}$ ions via the carboxylate groups, which are then directly involved in electrostatic interactions with the triphosphate esters of the nucleotide substrates [79]. INSTIs such as elvitegravir bind to the $\mathrm{Mg}^{2+}$ ions, and interrupt substrate binding $[80,81]$.

Elvitegravir (9) has a bicyclic carbamoyl 4-pyridone structure [80]. The aromatic ring with both chlorine and fluorine substituents give the molecule a hydrophobic tail, with a flexible linker connecting to the second ring system. The free carboxylate binds to $\mathrm{Mg}^{2+}$ ions in the active site of the HIV-1 IN [82]. Notably the 2-fluoro group was found to significantly improve inhibition of DNA stand transfer $\left(\mathrm{IC}_{50}=43.5 \mathrm{nM}\right)$ relative to the non-fluorinated analogue $\left(\mathrm{IC}_{50}=1.6 \mu \mathrm{M}\right)$ indicating an impressive enhancement with fluorine [71].

Elvitegravir (9) is administered as a single enantiomer. The basic patent procedure (Scheme 21) for its synthesis starts from 2,4-difluorobenzoic acid (72) [83,84]. This is first aryl-iodinated with $\mathrm{N}$-iodosuccinimide, and then converted to an acid chloride and then progressed with ethyl 3- 
(dimethylamino)acrylate to give acrylate 73. The dimethylamino group is replaced with $(S)$-valinol, and introduces a stereogenic centre. The enamine is then cyclized using potassium carbonate, following by silyl ether protection of the alcohol to form 74. A palladium-catalyzed Negishi coupling reaction through the aryl iodide with 2-fluoro-3-chlorobenzylzinc bromide gave $\mathbf{7 5}$. The ester was then hydrolyzed to form a carboxylic acid and the fluoroquinolone underwent a $\mathrm{S}_{\mathrm{N}} \mathrm{Ar}$ reaction with methoxide to generate elvitegravir 9 [71].<smiles>CCOC(=O)/C=C/N(C)C</smiles><smiles></smiles>

74

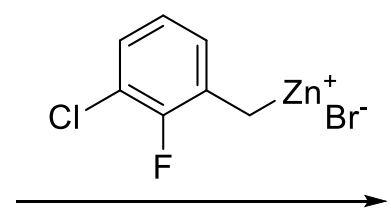

$[\mathrm{Pd}]$<smiles>CCOC(=O)c1cn([C@@H](CO)C(C)C)c2cc(F)c(Cc3cccc(Cl)c3F)cc2c1=O</smiles>

75

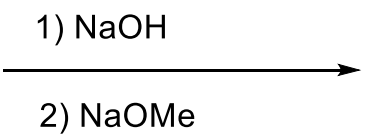<smiles>COc1cc2c(cc1Cc1cccc(Cl)c1F)c(=O)c(C(=O)O)cn2[C@@H](CO)C(C)C</smiles>

Elvitegravir (9)

Scheme 21. Initial patent procedure for the synthesis of elvitegravir 9.

\section{Enzalutamide (Xtandi ${ }^{\mathrm{TM}}$ )}

Enzalutamide 10 (Figure 7, previous names: RD162', MDV3100) was discovered at the University of California [85] and developed by Medivation and Astellas Pharma [86]. It was approved by the 
FDA for the treatment of metastatic castration-resistant prostate cancer after docetaxel therapy in 2012 and before docetaxel therapy in 2014 [87]. The indication was further extended to nonmetastatic castration-resistant prostate cancer in 2018 [88] and to metastatic castration-sensitive prostate cancer in 2019. Enzalutamide $\mathbf{1 0}$ is effective, safe, and generally well-tolerated. The most common adverse effects are fatigue, nausea, and anorexia, however, seizures are rarely reported [88]. Enzalutamide (Xtandi ${ }^{\mathrm{TM}}$ ) achieved sales of $\$ 3.62$ billion in 2018, marketed by Astellas Pharma and Pfizer.

Enzalutamide $\mathbf{1 0}$ is an androgen receptor (AR) antagonist. The AR is located in the cell cytoplasm, but after binding its ligand (testosterone, dihydrotestosterone or other androgenic steroids) the receptor is translocated into the nucleus and forms a homodimer, which stimulates expression of various genes. Physiological responses mediated by this AR signaling include prostate growth and differentiation, and almost all prostate cancers depend on AR signaling. This discovery led to androgen deprivation therapy, which is especially important in the treatment of advanced or metastatic prostate cancers. Androgen deprivation can be achieved by surgical or medical castration (decreasing testosterone production of the testicles), by blocking androgen biosynthesis (decreasing testosterone production in body as a whole) or by androgen receptor antagonists like enzalutamide (interfering with binding of androgens to AR) [87,89].

It is common that patients' response to androgen deprivation therapy declines after 18-36 months, a progression to a castration-resistant form [87]. In most cases, castration-resistant prostate cancer still requires AR signaling to survive and resistance to androgen deprivation therapy is achieved via overexpressing AR [87-89] or production of mutant ARs which are not inhibited, but activated by the prescribed anti-androgen [90]. In order to avoid these problems, development of 
enzalutamide 10 started from RU59063 (76) whose affinity to AR is only 3 times lower than testosterone and has high selectivity for AR over other nuclear hormone receptors. Since the 4cyano-3-trifluoromethylphenyl moiety present in $\mathbf{7 6}$ and the related 4-nitro-3-trifluoromethylphenyl moiety are common structural elements amongst nonsteroidal AR inhibitors, development focused on other parts of the molecule. It was found that the hydroxyalkyl motif of RU59063 can be replaced with a wide variety of 4-substituted phenyl groups without losing activity. Compound 77 with a 4tolyl group was chosen for further development. Changing the alkyl groups of the thiohydantoin ring led to compound $\mathbf{7 8}$, which was slightly more potent than $\mathbf{7 7}$ in vivo. However, $\mathbf{7 8}$ also has a short half-life with very quick clearance, which is attributed to its relatively high clogP value, and the fast metabolic oxidation of the $\mathrm{Ar}_{-} \mathrm{CH}_{3}$ group. Replacement of the methyl group with more polar motifs led to compound 79, which still suffered from poor pharmacokinetics. The suspected cause was metabolic oxidation of the electron-rich aromatic ring. To avoid this, the electron-withdrawing CONHMe group was attached directly to the ring and an electron-withdrawing fluorine atom was also introduced. The resulting compound $\mathbf{8 0}$ was quite potent and had a very good pharmacokinetic profile. Further development resulted in enzalutamide (10), which was slightly more active. Scheme 22 summarizes the development process described above [85,91]. 
<smiles>CC1(C)C(=O)N(c2ccc(C#N)c(C(F)(F)F)c2)C(=S)N1CCCCO</smiles>

RU59063 (76): no inhibition<smiles>Cc1ccc(N2C(=S)N(c3ccc(C#N)c(C(F)(F)F)c3)C(=O)C23CCC3)cc1</smiles>

$78\left(\mathrm{IC}_{50}=124 \mathrm{nM}\right)$<smiles>CNC(=O)c1ccc(N2C(=S)N(c3ccc(C#N)c(C(F)(F)F)c3)C(=O)C23CCC3)cc1F</smiles>

$80\left(\mathrm{IC}_{50}{ }^{*}=122 \mathrm{nM}\right)$<smiles>Cc1ccc(N2C(=S)N(c3ccc(C#N)c(C(F)(F)F)c3)C(=O)C2(C)C)cc1</smiles>

$77\left(\mathrm{IC}_{50}=125 \mathrm{nM}\right)$<smiles>CNC(=O)CCCc1ccc(N2C(=S)N(c3ccc(C#N)c(C(F)(F)F)c3)C(=O)C23CCC3)cc1</smiles>

$79\left(\mathrm{IC}_{50}=92 \mathrm{nM}\right)$<smiles>CNC(=O)c1ccc(N2C(=S)N(c3ccc(C#N)c(C(F)(F)F)c3)C(=O)C2(C)C)cc1F</smiles>

enzalutamide (10)

Figure 7. Development of enzalutamide 10 showing previous lead candidates 76-80. I $n$ vitro $\mathrm{IC}_{50}$ values are given in brackets.

The first published synthesis of enzalutamide $\mathbf{1 0}$ had a number of drawbacks. Many toxic and/or corrosive reagents $\left(\mathrm{CrO}_{3}, \mathrm{SOCl}_{2}\right.$, thiophosgene, acetone cyanohydrin) were used and the yield of the final step (creation of the thiohydantoin ring by the reaction of isothiocyanate $\mathbf{8 2}$ with an $\alpha$-aminonitrile) was poor (25\% was later improved to $51 \%$ ) [85,91]. Medivation patented a better route in 2011, which solved many of the above problems. Aminonitrile 81 was converted to isothiocyanate $\mathbf{8 2}$ with thiophosgene as a key intermediate. 4-Bromo-2-fluorobenzoic acid $\mathbf{8 3}$ was transformed to $\mathrm{N}$-methylamide $\mathbf{8 4}$ and which was converted to the $\mathrm{N}$-arylated 2-aminoisobutyric acid. The resulting amino acid $\mathbf{8 5}$ was methylated to give ester $\mathbf{8 6}$ which, upon reaction with isothiocyanate 82, gave enzalutamide 10 in $82 \%$ yield and high purity (Scheme 22) [92]. 

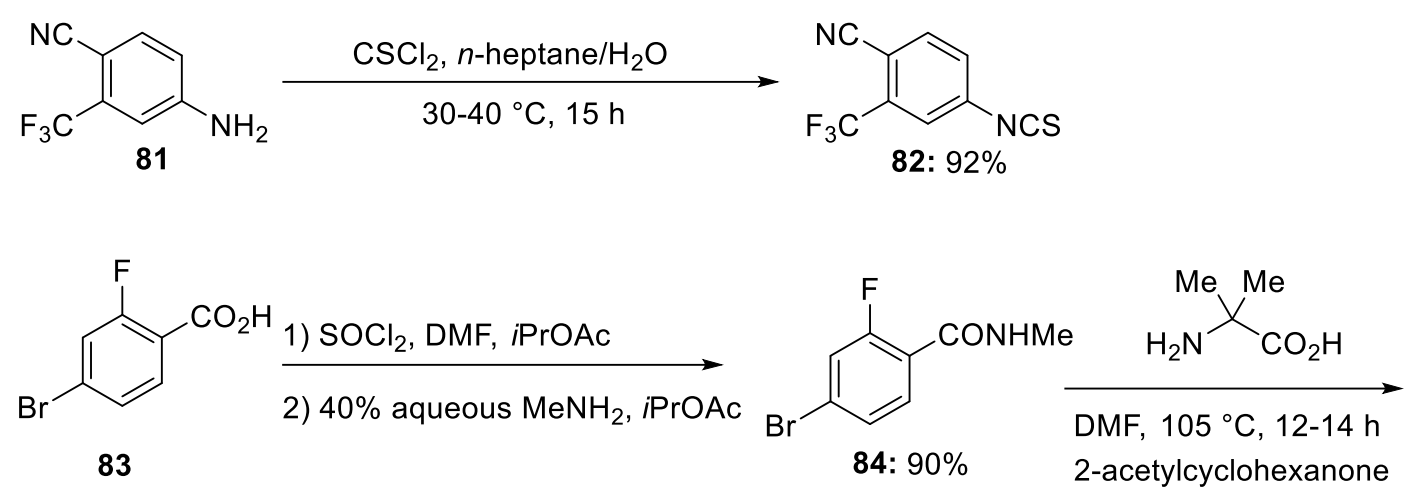

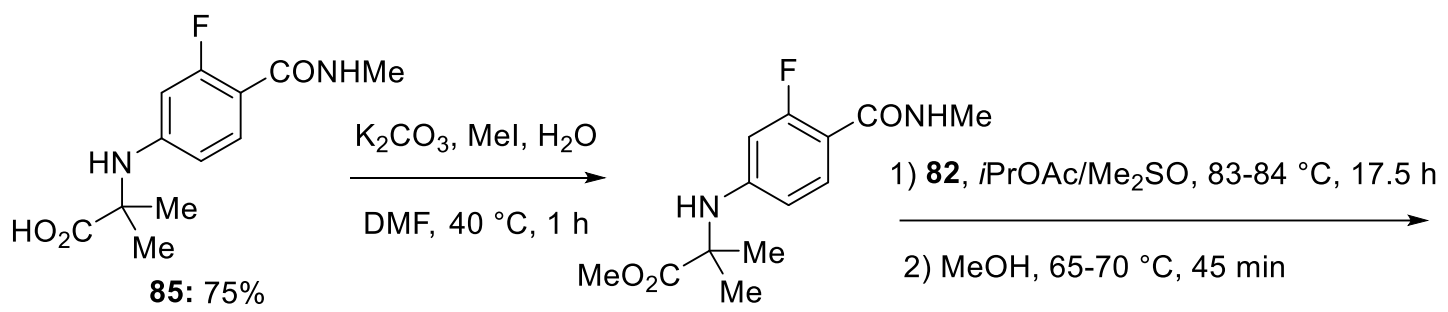

86: $95 \%$<smiles>CNC(=O)c1ccc(N2C(=S)N(c3ccc(C#N)c(C(F)(F)F)c3)C(=O)C2(C)C)cc1F</smiles>

enzalutamide (10): $82 \%$

Scheme 22 Medivation's route to enzalutamide (10).

In 2015, Zentiva patented a slightly different and shorter synthesis. Amino acid $\mathbf{8 5}$ was obtained from the fluoro-nitrobenzoic acid $\mathbf{8 7}$ via amidation, reduction of the nitro group, and $\mathrm{N}$ alkylation with 2-bromoisobutyric acid. Reaction of isothiocyanate $\mathbf{8 2}$ with carboxylic acid $\mathbf{8 5}$ gave enzalutamide (10) together with its hydantoin analogue. Their highly similar physical-chemical properties makes the removal of the hydantoin impurity difficult, but formation of the byproduct can be suppressed with a phenol additive (Scheme 23), and the level of hydantoin in the final product can be lowered to $0.08 \%$ [93]. 


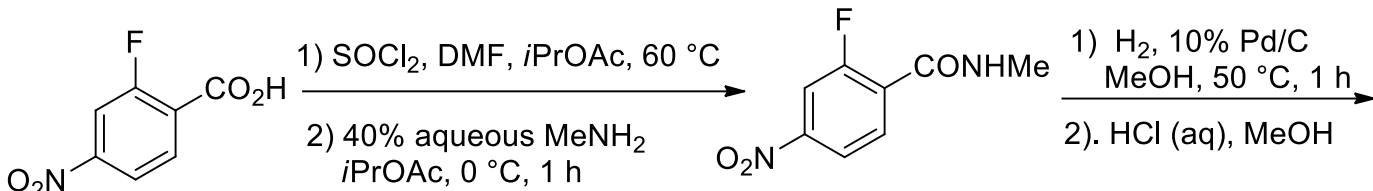

87

88: $90 \%$
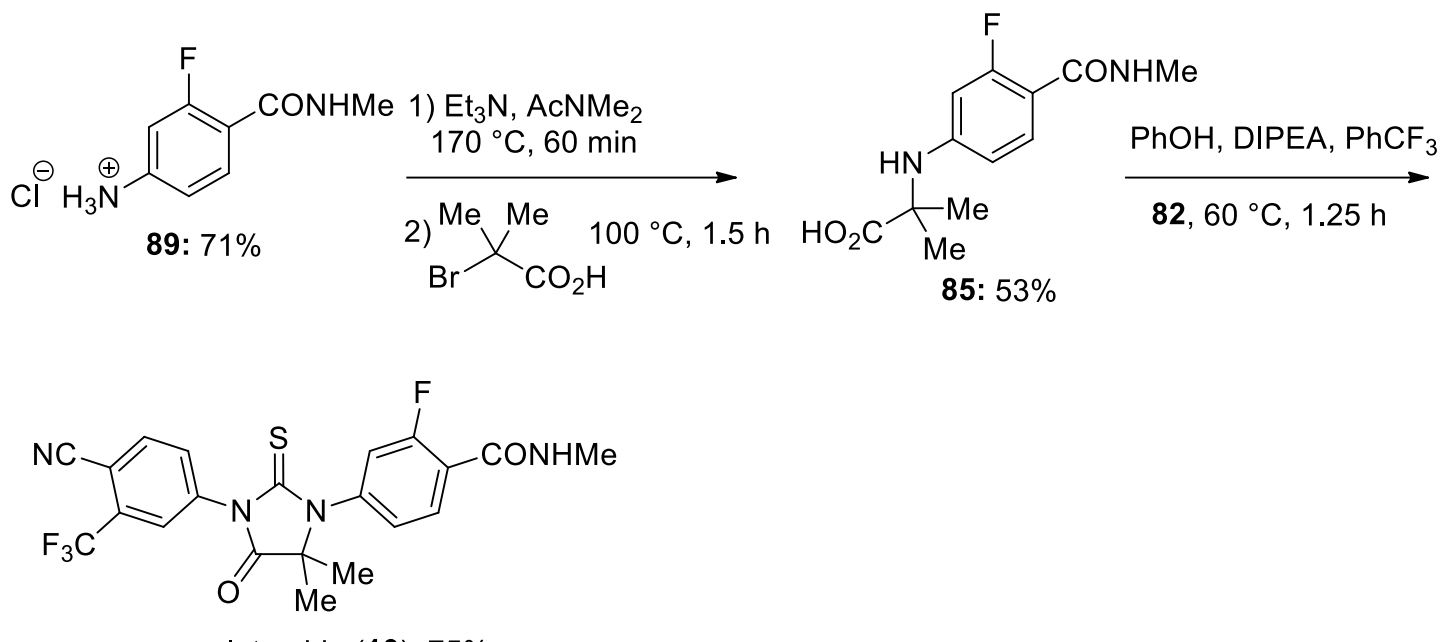

enzalutamide (10): $75 \%$

Scheme 23. Zentiva's route to enzalutamide (10).

The reaction of compounds $\mathbf{8 2}$ and $\mathbf{8 5}$ can also be facilitated by BSA [N,Obis(trimethylsilyl)acetamide] (Scheme 24) [94].

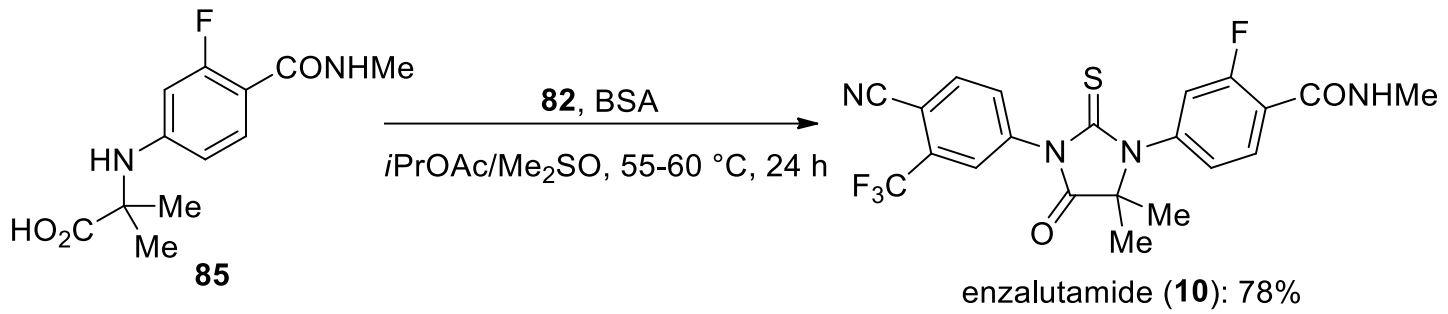

Scheme 24. Last step in the synthesis of enzalutamide $\mathbf{1 0 .}$

All of the above methods use thiophosgene, which is a highly toxic liquid. Alternatively, amine

$\mathbf{8 1}$ can be transformed into isothiocyanate $\mathbf{8 2}$ in a multistep procedure using $\mathrm{NH}_{4} \mathrm{SCN}, \mathrm{PhCOCl}$, and $\mathrm{NaOH}$ [95]. Isothiocyanate $\mathbf{8 2}$ can also be replaced with the related reagent methyl dithiocarbamate, which can be obtained from amine 81 in 2 steps (reaction with $\mathrm{CS}_{2}$ and $\mathrm{DBU}$, 
followed by treatment with MeI) [96].

\section{Dolutegravir}

Dolutegravir (11) is also an HIV-integrase inhibitor and acts on the strand transfer step during HIV1 genome integration into the hosts chromosome (Figure 8) [97]. Dolutegravir was co-developed by GlaxoSmithKline and Shionogi and was approved for the clinic by the FDA in 2013 [98]. Dolutegravir 11 is highly potent, having an $\mathrm{IC}_{50}$ of $2.7 \mathrm{nM}$ and an $\mathrm{EC}_{50}$ of $0.51 \mathrm{nM}$, and exhibits greater potency than elvitegravir [99]. Additionally, it has a terminal half-life of 14 hours [100]. Dolutegravir dissociates more slowly than elvitegravir from the integrase-DNA complexes [101]. All of this means that dolutegravir presents a higher barrier to resistance development in-vitro [102], and unlike Elvitegravir it does not need to be taken with a pharmacokinetic booster [103]. It is administered on its own by single, daily dose. As a result of these benefits, dolutegravir is currently on the World Health Organization's list of essential medicines.<smiles>CC1CCO[C@H]2Cn3cc(C(=O)NCc4ccc(F)cc4F)c(=O)c(O)c3C(=O)N12</smiles>

Figure 8. Structure of dolutegravir.

Dolutegravir $\mathbf{1 1}$ has also been developed as a component of the combination drug Triumeq [104]. Triumeq also contains the reverse transcriptase inhibitors, abacavir and lamivudine. Triumeq was developed by ViiV Healthcare and was approved by the FDA for use in the United States in 
2014. Triumeq is administered as a single tablet taken once daily and the treatment exhibits a high barrier to resistance. In 2018 it grossed sales of $\$ 4.4$ billion.

Dolutegravir $\mathbf{1 1}$ is primarily metabolized by uridine diphosphate glucuronosyltransferase (UGT1A1) and to a lesser extent by cytochrome P450 (CYP450) activity [105]. It does not inhibit or induce UGT1A1 or CYP450 enzymes at clinically relevant concentrations [106]. Dolutegravir has a tricyclic carbamole pyridine structure [80]. Like elvitegravir, dolutegravir contains a hydrophobic tail, in this case as a 2,4-difluorobenzyl moiety and it coordinates active site $\mathrm{Mg}^{2+}$ associated with HIV-1 IN, through its enolisable oxygens [80].

Dolutegravir $\mathbf{1 1}$ is prepared as a single diastereoisomer in an enantiomerically pure form. The original Shionogi synthesis (Scheme 25 and 26) described a 16 step protocol with an overall yield of $2 \%$. In summary, etherification of maltol (90) gave 91 which was treated with ammonia to generate 4-pyridone 92. Selective bromination with N-bromosuccinimide gave $\mathbf{9 3}$ as a substrate for palladium-catalyzed carbonylation. The resultant ester $\mathbf{9 4}$ was protected and then oxidized to give pyridine $\mathrm{N}$-oxide 96, in order to mediate an ortho-methyl oxidation by $\mathrm{N}$-oxide acetylation and [3.3] sigmatropic rearrangement. Product tri-ester $\mathbf{9 7}$ was then hydrolyzed to give advanced intermediate 98. 


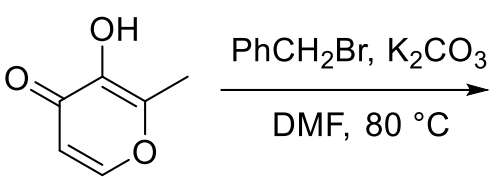

90

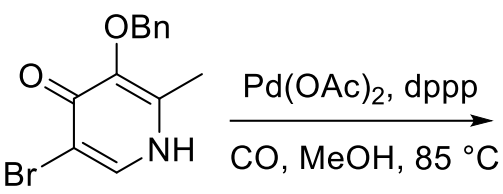

93<smiles>Cc1occc(=O)c1OCc1ccccc1</smiles>

91<smiles>Cc1[nH]ccc(=O)c1OCc1ccccc1</smiles>

92<smiles>COC(=O)c1cnc(C)c(Cc2ccccc2)c1O</smiles>

94<smiles>COC(=O)c1cnc(C)c(OCC(=O)OCc2ccccc2)c1OCC(C)(Cl)Br</smiles>

95
96<smiles>COC(=O)c1c[n+]([O-])c(C)c(OCC(C)=O)c1OCC(C)C</smiles><smiles>COC(=O)c1cnc(COC(C)=O)c(OC(C)=O)c1OC(C)=O</smiles><smiles>O=C(O)c1cnc(CO)c(Br)c1O</smiles>

Scheme 25. Synthesis of intermediate 98 in the base patent synthesis of dolutegravir 11.

Intermediate $\mathbf{9 8}$ was progressed to amide $\mathbf{1 0 0}$ and the primary alcohol of $\mathbf{1 0 0}$ was sequentially oxidized to carboxylic acid 102. Esterification gave methyl ester 103, and then $\mathrm{N}$-allylation afforded 4-pyridone 104. Selective oxidative olefin cleavage, generated aldehyde hydrate $\mathbf{1 0 5}$. This hydrate was treated with $(R)$-3-aminobutan-1-ol, forming two acetal diastereoisomers. Diastereoselective aminal ring closure generated the $(S, R)$-diastereomer with high selectivity and this progressed an intramolecular attack of the amine onto the ester moiety, to form lactam 106. Debenzylation gave dolutegravir (11), which is administered as its sodium salt (110), after neutralization. 
<smiles>O=C(O)c1cnc(CO)c(OCc2ccccc2)c1O</smiles>

98

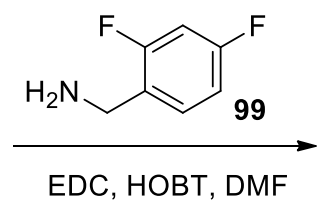

EDC, HOBT, DMF<smiles>CCC(C)OC(=O)c1cnc(CO)c(O)c1C(=O)NCc1ccc(F)cc1F</smiles>

$\mathrm{MnO}_{2}, \mathrm{CHCl}_{3}$

100<smiles>O=C(NCc1ccc(F)cc1F)c1cnc(C(=O)O)c(OCc2ccccc2)c1O</smiles><smiles>COc1c(C(=O)O)ncc(C(=O)NCc2ccc(F)cc2F)c1O</smiles>

102

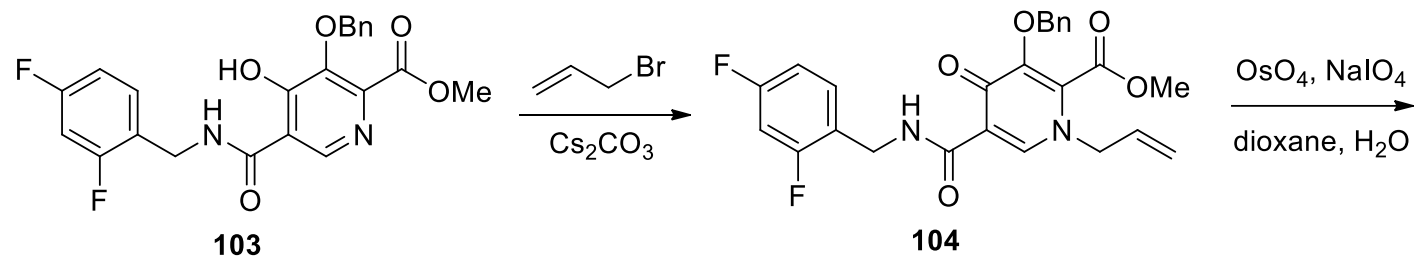<smiles>CCOc1c(C(=O)OC)n(CC(O)O)cc(C(=O)NCc2ccc(F)cc2F)c1=O</smiles><smiles>CC(=O)OC(C)(N)CCO</smiles>

$\mathrm{AcOH}, 140^{\circ} \mathrm{C}$<smiles>C[C@@H]1CCO[C@H]2Cn3cc(C(=O)NCc4ccc(F)cc4F)c(=O)c(Cc4ccccc4)c3C(=O)N21</smiles>

106

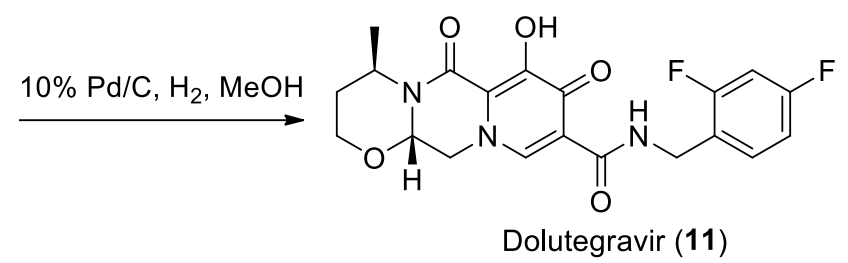

Scheme 26. Base patent synthesis of dolutegravir.

An alternative route was developed by Micro Labs as illustrated in Scheme 27 [107]. Pyran 107, previously prepared in a three-step protocol, was treated with 2,2-dimethoxyethanamine to give 4-pyridone 108, which was progressed to amide 109. Acetal deprotection followed by treatment with (3R)-aminobutan-1-ol resulted in heterocyclisation and generated both stereogenic centers with the formation of intermediate 106. Unlike the route in Scheme 25, benzyl deprotection was achieved with TFA in DCM and the product, as a free carboxylic acid, was recovered by crystallization from 
toluene. Treatment with sodium hydroxide in methanol gave sodium dolutegravir (110) as the active pharmaceutical ingredient [108].<smiles>CC(=O)c1coc(C(=O)O)c(OCc2ccccc2)c1=O</smiles>

107

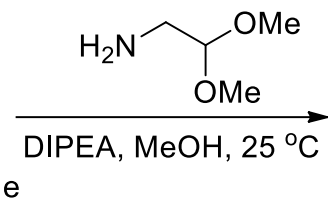

OBn O<smiles>CCOc1c(C(=O)OC)n(CC(OC)OC)cc(C(=O)NCc2ccc(F)cc2F)c1=O</smiles>

109<smiles>CCOc1c(C(=O)OC)n(CC(OC)OC)cc(C(=O)OC)c1=O</smiles>

108<smiles>CC(=O)OC(C)C</smiles>

$\mathrm{AcOH}$, toluene, $90^{\circ} \mathrm{C}$

1) $\mathrm{CF}_{3} \mathrm{CO}_{2} \mathrm{H}, \mathrm{DCM}, 35^{\circ} \mathrm{C}$

2) toluene, $80^{\circ} \mathrm{C}$

3) $\mathrm{NaOH}, \mathrm{H}_{2} \mathrm{O}, \mathrm{MeOH}, 65^{\circ} \mathrm{C}$<smiles>CC1CCO[C@H]2Cn3cc(C(=O)NCc4ccc(F)cc4F)c(=O)c(O[N+](=O)[O-])c3C(=O)N12</smiles>

Scheme 27. Alternative synthesis to sodium dolutegravir 110 developed by Micro Labs.

\section{Bictegravir}

Bictegravir (12) is another HIV-1 integrase inhibitor (Figure 9). Like elvitegravir and dolutegravir, bictegravir inhibits the strand transfer step of integration of virally coded DNA into the hosts genome. The drug was developed by Gilead Sciences and is administered as a component of the combination drug Biktarvy, also developed by Gilead Sciences. Biktarvy contains the nucleoside reverse transcriptase inhibitors emtricitabine and tenofovir alafenamide in addition to bictegravir [109]. Bictegravir exhibits a high in-vitro barrier to resistance and also has a terminal half-life of around 18 hours, and as a consequence is not prescribed with a pharmacokinetic booster [110]. It is metabolized primarily by CY3PA and UGT1A1 [111]. Biktarvy was first approved for use in the 
USA by the FDA in February 2018 and soon after for the EU in June 2018. Biktarvy grossed sales in its first year of $\$ 1.18$ billion and then $\$ 4.7$ billion in 2019 , and appears to be on a steep trajectory in commercial terms.

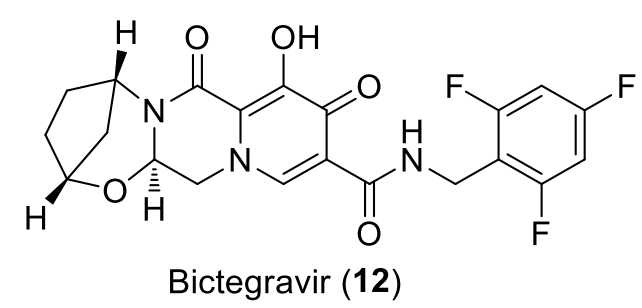

Figure 9. Structure of the HIV integrase inhibitor bictegravir 12.

Bictegravir (12) is an INSTI, and like dolutegravir also contains a tricyclic carbamoyl 4pyridone structure. However, it is unique in that it has a peripheral bridged oxazepane ring with a methylene bridge [112]. This flexible ring is thought to contribute to the efficacy of bictegravir, as it allows the drug to readily adapt conformation, to changes in the geometry of the IN active site [113]. Bictegravir contains three stereogenic centres, and it also has a peripheral hydrophobic aromatic moiety common to this class of drugs.

The patent synthesis for bictegravir developed by Gilead begins with 4-pyridone $\mathbf{1 1 1}$ as a precursor to aldehyde 112. Treatment with $(1 R, 3 S)$-3-aminocyclopentanol (113) generates tricycle 114. With three stereogenic centres in place, carboxylic acid $\mathbf{1 1 4}$ is progressed to amide $\mathbf{1 1 6}$ after coupling with 2,4,6-trifluorobenzylamine (115). Methyl ether cleavage with $\mathrm{MgBr}_{2}$ generated the active product, bictegravir (12) (Scheme 28). 
<smiles>COC(=O)c1c(OC)c(=O)c(C(=O)O)cn1CC(OC)OC</smiles>

111
$\mathrm{AcOH}, \mathrm{MeSO}_{3} \mathrm{H}$

$\mathrm{MeCN}, 75^{\circ} \mathrm{C}$<smiles>COC(=O)c1c(OC)c(=O)c(C(=O)O)cn1CC=O</smiles>

112
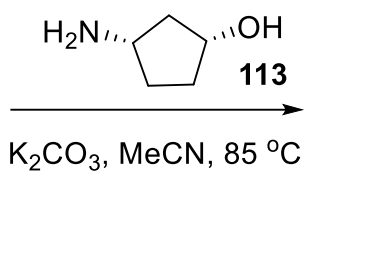

$$
\text { . }
$$<smiles>NCc1c(F)cc(F)cc1F</smiles>

HATU, DIPEA, MeCN

114

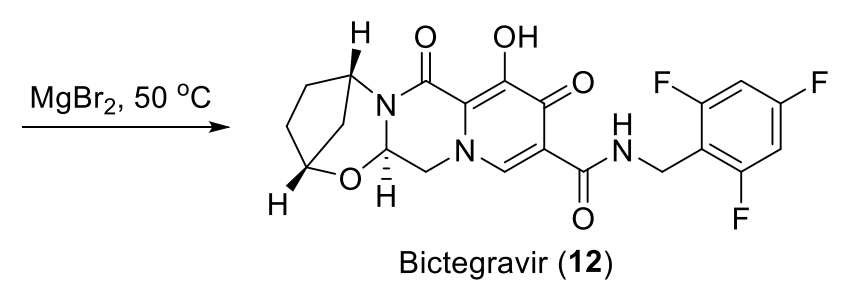

Scheme 28. Original patent synthesis of HIV integrase inhibitor bictegravir 12.

Gilead developed an improved seven-step route to bictegravir (Scheme 29) [108]. In this route Meldrum's acid was reacted with activated methoxyacetic acid to generate acylated intermediate 118 and then treatment with trifluorobenzylamine (115) resulted in $\beta$-ketoamide 119. Enamine 120 was formed after reaction with 2,2-dimethoxyethan-1-amine, which then cyclized in a reaction with dimethyl oxalate to form 4-pyridone 121. The required bicyclic ring system was installed when 121 was treated with the oxalate or benzoate salt of $(1 R, 3 S)$-3-aminocyclopentanol, and this generated 116 as the penultimate intermediate. Methyl ether cleavage again gave bictegravir (12). 

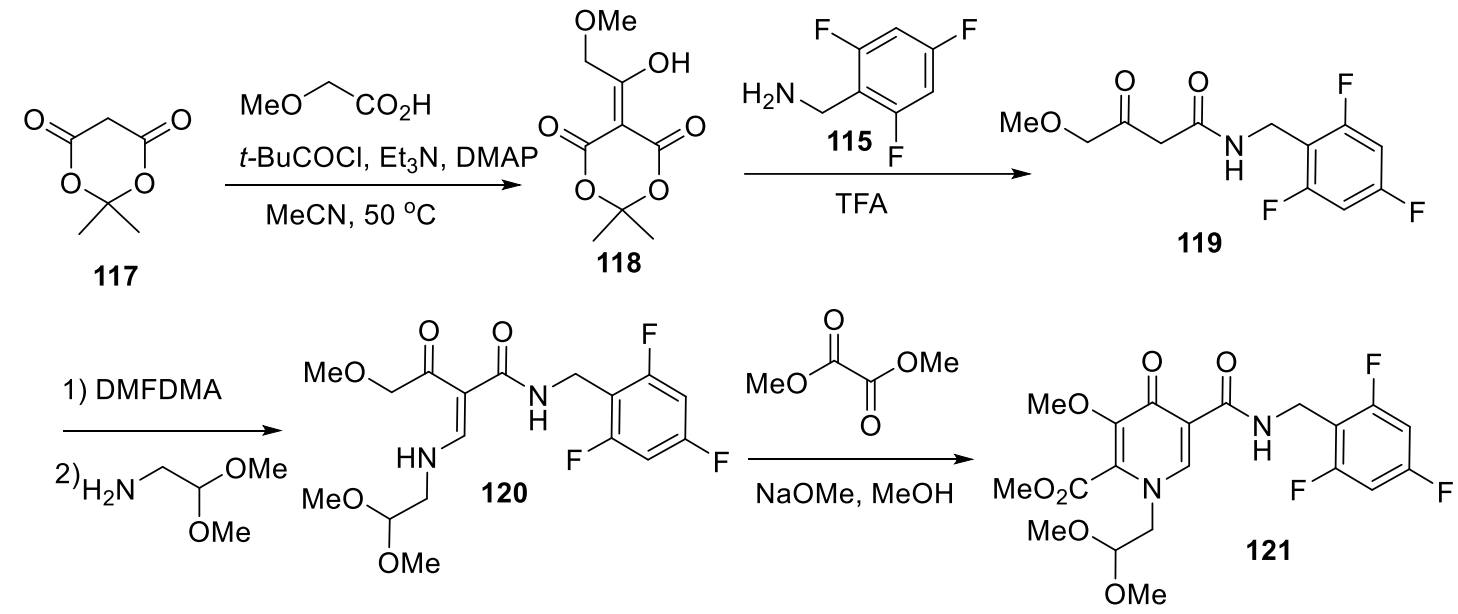

1) $\mathrm{AcOH}, \mathrm{MeSO}_{3} \mathrm{H}, \mathrm{MeCN}, 75^{\circ} \mathrm{C}$

2) $\mathrm{H}_{2} \mathrm{~N}_{1} . r_{113} \mathrm{OH}$ (oxalate salt) $\mathrm{K}_{2} \mathrm{CO}_{3}, 75^{\circ} \mathrm{C}$<smiles>O=C(NCc1c(F)cc(F)cc1F)c1cn2c(c(O)c1=O)C(=O)N1C3CCC(CC3)OC1C2</smiles>

Bictegravir (12)

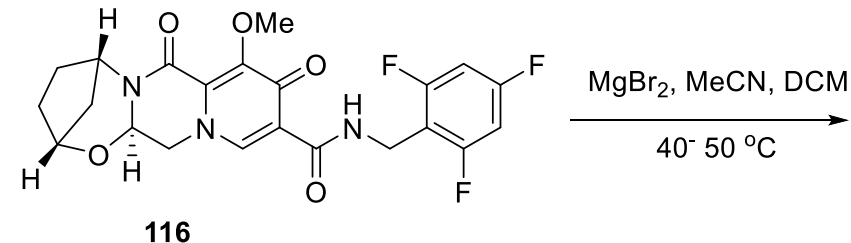

116

Scheme 29. Improved synthesis of HIV integrase inhibitor bictegravir 12 by Gilead Sciences.

\section{Emtricitabine}

Emtricitabine (13) is an L-oxathiolanyl nucleoside derivatives (Figure 10), which was developed as a nucleoside reverse-transcriptase inhibitor. Structure-activity relationships (SAR) disclosed that fluorine substitution at C5- of the cytosine moiety is essential for the anti-HIV activity (13, antiHIV-1 in PBM cells, $\mathrm{EC}_{50}=1.3 \mathrm{nM}$ ). More than $2 \times 10^{3}$ fold lower activity was found when the fluorine atom was replaced by chlorine at $\mathrm{C} 5\left(\mathbf{1 3 A}, \mathrm{EC}_{50}=31.8 \mu \mathrm{M}\right)$ [114]. 
<smiles></smiles>

emtricitabine (13)

$\mathrm{EC}_{50}=0.0013 \mu \mathrm{M}$<smiles></smiles>

13A

$\mathrm{EC}_{50}=31.8 \mu \mathrm{M}$<smiles></smiles>

13B

$\mathrm{EC}_{50}=1.90 \mu \mathrm{M}$

Figure 10. Structure of emtricitabine (13) and related anti-HIV compounds.

Emtricitabine (13) has been successfully used as an active ingredient in several blockbuster drugs. Biktarvy ${ }^{\mathrm{TM}}$ is a combination drug containing emtricitabine and two other active ingredients, bictegravir and tenofovir alafenamide, which was approved in 2018 as a complete regimen for the treatment of HIV-1 infection in adults [109]. In 2019, Biktarvy ${ }^{\mathrm{TM}}$ grossed $\$ 4.7$ billion in sales (ranked 16). Emtricitabine $\mathbf{1 3}$ is also used as a component of other anti-HIV combination drugs, including Truvada (emtricitabine/tenofovir disoproxil fumarate, Gilead Sciences), Atripla (efavirenz/emtricitabine/tenofovir disoproxil fumarate, Gilead Sciences és and Bristol-Myers Squibb) and Genvoya (elvitegravir/cobicistat/emtricitabine/tenofovir alafenamide, Gilead Sciences).

The process for the preparation of emtricitabine (13) is presented in Scheme 30 [115], and involves the key quaternary ammonium salt intermediate 124. Treatment of 5-hydroxy[1,3] oxathiolane-2-carboxylic acid menthol ester 122 and thionyl chloride in the presence of methanesulfonic acid and DMF, followed by substitution with 2-mercaptopyridine gave intermediate $\mathbf{1 2 3}$, which was $\mathrm{N}$-alkylated with ethyl iodide to generate pyridinium $\mathbf{1 2 4}$. Introduction of the pyrimidine base in protected form gave 125, and then deacetylation gave free amine $\mathbf{1 2 6}$. The ester moiety was reductively cleaved with $\mathrm{NaBH}_{4}$ to afford the core structure which was formulated through various salts exchanges to afford emtricitabine (13). 


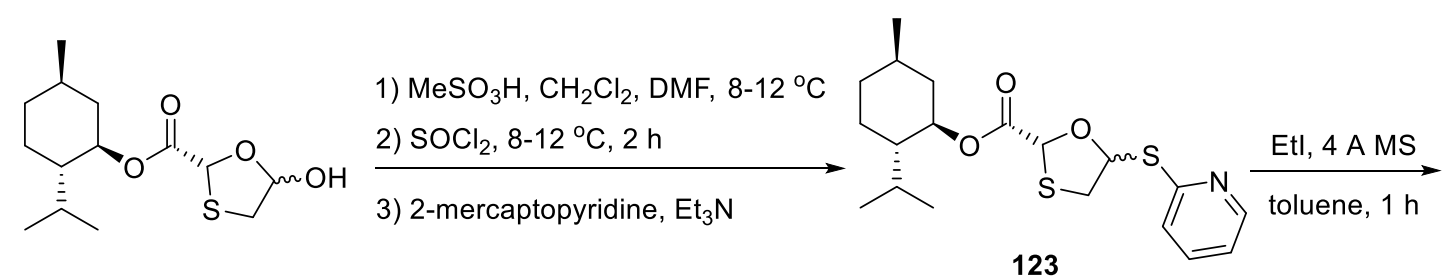

122<smiles>CC[n+]1ccccc1S[C@H]1CS[C@H](C(=O)O[C@H]2C[C@H](C)CC[C@H]2C(C)C)O1</smiles><smiles>CC(=O)Nc1nc(=O)[nH]cc1F</smiles>

1) $\mathrm{HMDS}, \mathrm{MeSO}_{3} \mathrm{H}$, toluene, reflux, 3-4 h 2) $124,75-80^{\circ} \mathrm{C}, 10 \mathrm{~h}$

3) $\mathrm{NaHCO}_{3}, 4-5 \mathrm{~h}$

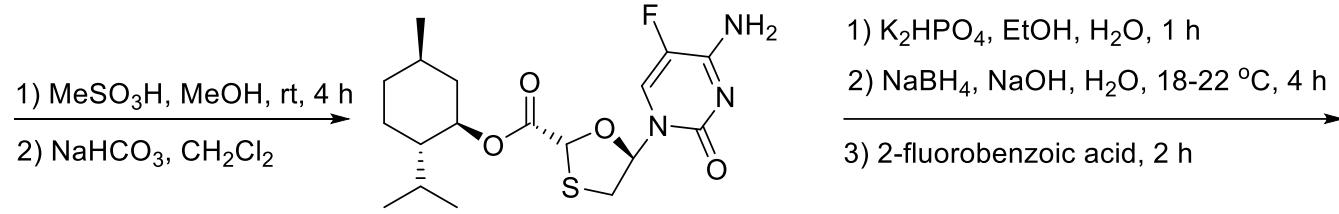

126

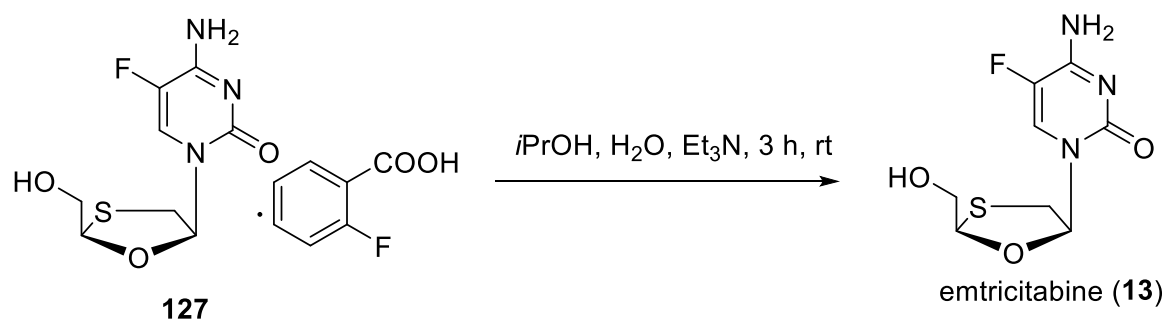

Scheme 30. Synthesis of the HIV reverse transcriptase inhibitor emtricitabine (13).

An enzymatic kinetic resolution process has also been developed for the preparation of emtricitabine (13). The hydrolytic ester resolution of racemic (+/-)-2',3'-dideoxy-5-fluoro-3'thiacytidine butyrate (128) was successfully demonstrated using an immobilized cholesterol esterase (accurel PP). In this manner emtricitabine (13) was obtained in high enantioselectivity (98\% ee) and good with a good recovery $(31 \%, 2.17 \mathrm{~kg})[116]$. 


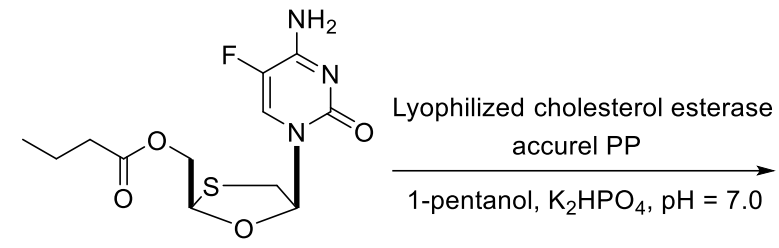

$(+/-)-428$

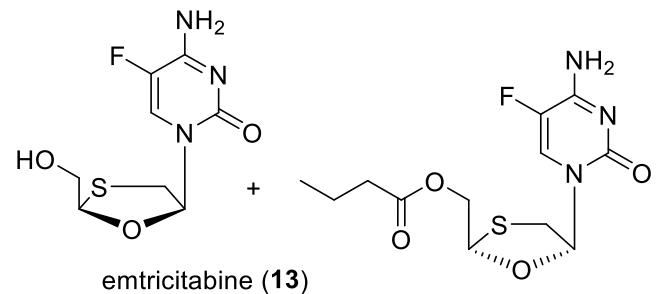

$(-)-128$

Scheme 31. Enzymatic kinetic resolution of butyrate 128 as a last step in the preparation of emtricitabine 13.

Such biocatalytic resolutions can be complicated by the SDE phenomenon [117] necessitating controlled SDE assays for the reliable determination of reported enantioselectivity values [118].

\section{Efavirenz}

Efavirenz (S)-14 (former names: L-743726, DMP-266) was discovered and developed by Merck as an anti-HIV medication (Figure 11) [119,120]. Clinical trials demonstrated good efficiency and tolerability and efavirenz was approved by the FDA in 1998 for the treatment of HIV-1 infections as a single drug $\left(\operatorname{Sustiva}^{\circledR}\right)$ [121]. In order to utilize synergistic effects and to reduce the development of drug resistance, it became more and more common to use combinations of anti-HIV drugs, preferably as fixed-dose drug combinations [122]. Examples of efavirenz-containing fixed-dose drug combinations are Atripla ${ }^{\circledR}$ (2006, efavirenz/emtricitabine/tenofovir disoproxil fumarate) [121] and $\operatorname{Symfi}^{\circledR}$ (2018, efavirenz/lamivudine/tenofovir disoproxil fumarate) [123]. 
<smiles>O=C1Nc2ccc(Cl)cc2[C@@](C#CC2CC2)(C(F)(F)F)O1</smiles>

Efavirenz (14)

Figure 11. Structure of the anti-HIV therapy efavirenz 14.

As a retrovirus, HIV-1 transfects its host with RNA that encodes all of the structural proteins and enzymes required for replication. During infection, the reverse transcriptase enzyme creates a double-strand DNA copy of the viral RNA. This DNA is then integrated into the host genome by the action of a virally encoded integrase enzyme which insert this foreign DNA with associated promoters and regulatory elements. The host cell can now efficiently express viral genes, with the capacity to synthesize more viral particles. Inhibition of HIV-1 reverse transcriptase is a viable strategy to suppress virus replication and the progress of HIV-1 infection [124]. Efavirenz is a nonnucleoside reverse transcriptase inhibitor (NNRTI). Such compounds bind to an allosteric site (a hydrophobic pocket) of the enzyme, inducing a conformational change, which interferes with protein function $[121,122]$. The role of the fluorine atoms in efavirenz $\mathbf{1 4}$ is to increase the acidity of the carbamate moiety, which forms an important hydrogen bonding interaction with the protein [125].

The first published synthesis of efavirenz 14 started from 4-chloroaniline. After pivaloylation, a directed ortho-lithiation reaction with ethyl trifluoroacetate and hydrolysis gave amino-ketone $\mathbf{1 3 0}$. Scheme 32 illustrates an improved version of this process. Amino-ketone $\mathbf{1 3 0}$ is then treated with 2-cyclopropylethynylmagnesium bromide or 1-lithio-2-cyclopropylacetylene, and ring closing of 
the resultan adduct with 1,1'-carbonyldiimidazole, generates racemic efavirenz [119,126]. Later, $N$ Boc-protected 4-chloroaniline (obtained via reaction of 4-chlorophenylisocyanate with $t \mathrm{BuOH}$ ) was subjected to ortho-lithiation, followed by treatment with ethyl trifluoroacetate, nucleophilic addition of 1-lithio-2-cyclopropylacetylene, and $n$ BuLi-promoted cyclization to obtain racemic efavirenz 14 [127]. In both cases, efavirenz 14 was resolved into its enantiomers via its (-)-camphanoylated derivative $[119,126,127]$.

In order to investigate more cost-effective syntheses, asymmetric approaches have been explored. Merck researchers discovered that nucleophilic addition of 1-lithio-2cyclopropylacetylene to generate $\mathbf{1 3 0}$ in the presence of chiral amino-alcohols offers some level of enantioselectivity [120], but better enantiomeric excesses were achieved with para-methoxybenzylprotected amino-ketone 131. The complete conversion of $\mathbf{1 3 1}$ required 2 equivalents of acetylide and 2 equivalents of the amino-alcohol. Using amino-alcohol 132, an outcome of $98 \%$ ee was achieved if the acetylide-amino-alkoxide solution was warmed to ca. $0{ }^{\circ} \mathrm{C}$ before cooling to $-55^{\circ} \mathrm{C}$ [128]. Without this cooling the ee dropped to $82 \%$ [120]. This was explained by the temperaturedependent nature of lithium aggregates where equilibration near $0{ }^{\circ} \mathrm{C}$ generated the dimeric species 133, which remained intact upon freezing and promoted the required enantioselective addition $[120,128]$. After alkynylation, amino-alcohol $\mathbf{1 3 2}$ was recovered in 98\% yield from the aqueous phase and product 134 was transformed into efavirenz $(S)-\mathbf{1 4}$ by cyclization mediated by the equivalent of phosgene and oxidative $N$-deprotection. After some further development [129], this route (Scheme 32) was used to obtain the necessary quantity of the drug for clinical trials, launch, and early sales of efavirenz [120]. 


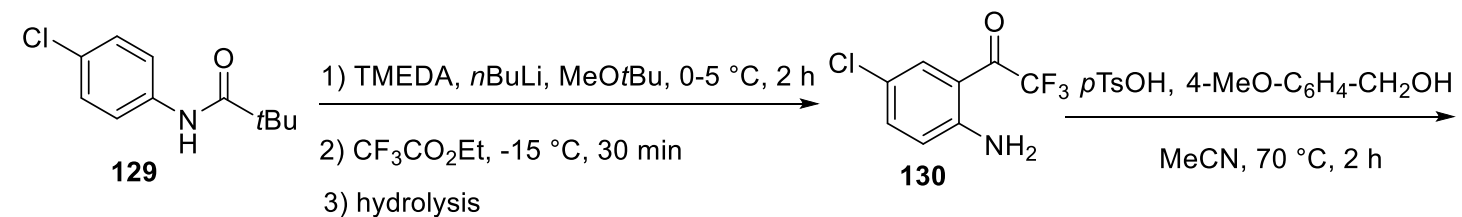<smiles>COc1ccc(CNc2ccc(Cl)cc2C(=O)C(F)(F)F)cc1</smiles>
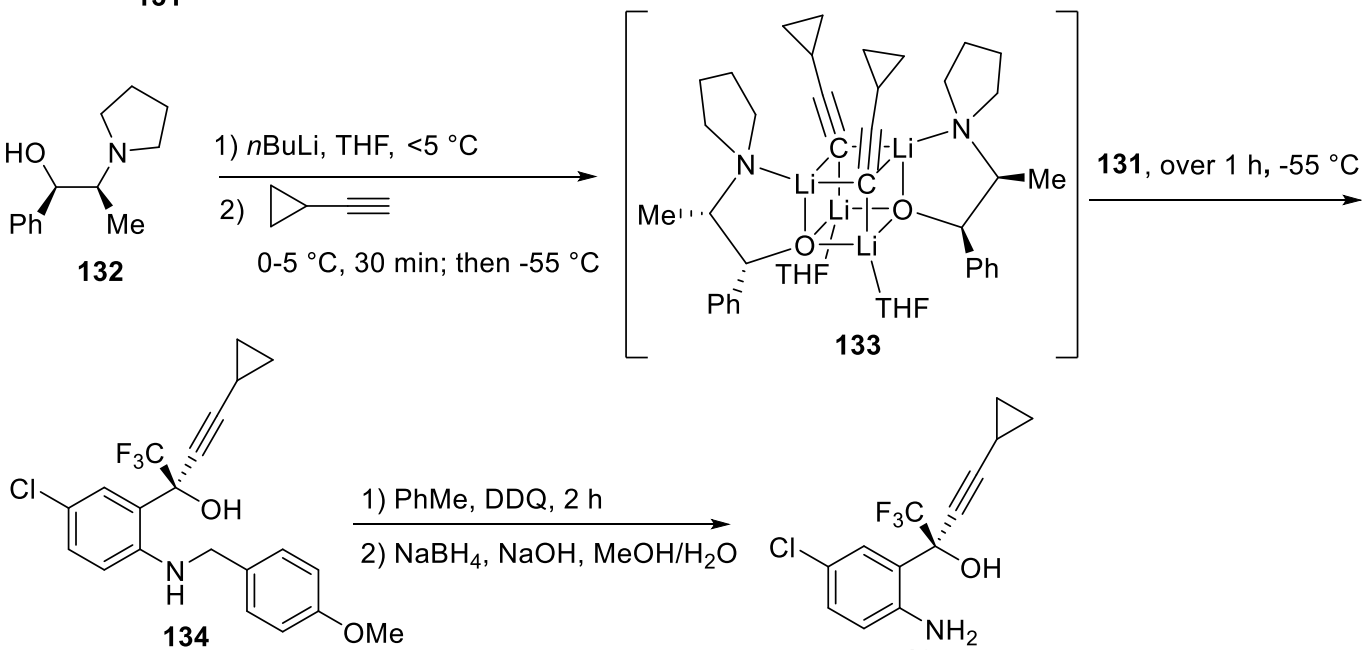

(>99\% purity, $>99.5 \%$ ee)

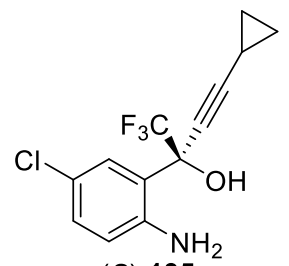

(S)-135

(>99.5\% purity)

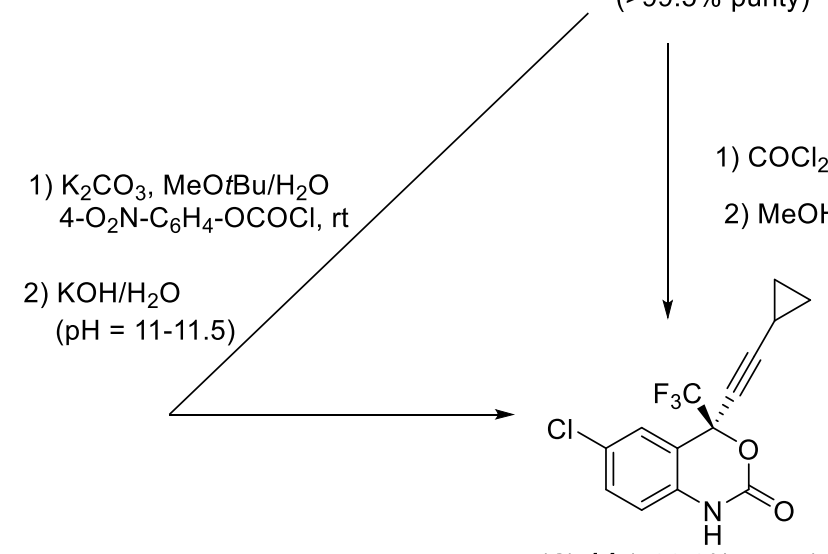

(S)-14 (>99.8\% purity)

Scheme 32. Asymmetric synthesis of efavirenz 14 using lithium amino-alkoxides.

Merck also explored the use of organozinc compounds but their basicity was low. It was found that mixing dialkylzinc with 1 equivalent ephedrine-derived amino-alcohol $\mathbf{1 3 2}$ and 1 equivalent of achiral auxiliary alcohol in any order produced an organozinc species, which upon treatment with a lithium or magnesium acetylide generated a zincate, which participated in the required reaction, 
with good efficiently and enantioselectivity. Optimized conditions gave $95 \%$ of analytically pure (S)-135 with an 99.3\% ee after recrystallization. Amine-alcohol $\mathbf{1 3 2}$ can be recovered from the aqueous phase at workup, (Scheme 33). Interestingly, this new method requires the free aromatic amino group to achieve high ee values, as product $\mathbf{1 3 4}$ was formed only with $45 \%$ ee from $\mathbf{1 3 1}$ $[120,130]$.

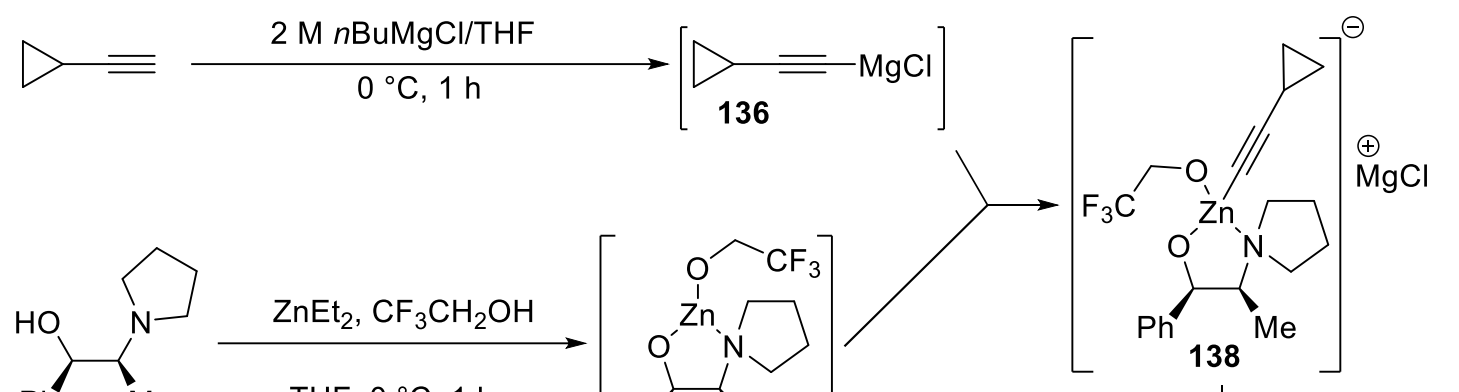
132

$\mathrm{THF}, 0{ }^{\circ} \mathrm{C}, 1 \mathrm{~h}$

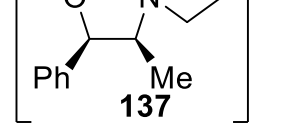<smiles>Nc1ccc(Cl)cc1C(=O)C(F)(F)F</smiles>
$0{ }^{\circ} \mathrm{C}, 15 \mathrm{~h}$<smiles>Nc1ccc(Cl)cc1C(O)(F)C#CC1CC1</smiles>

(S)-135
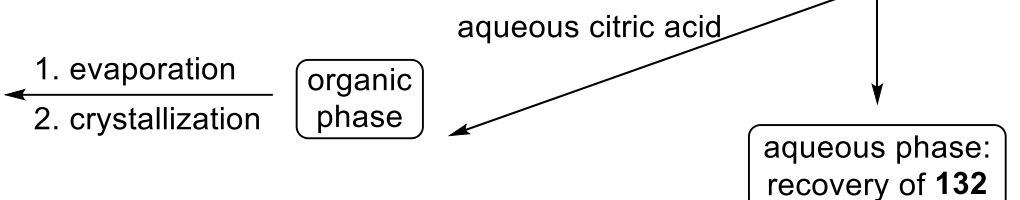

(99.9\% purity, $99.3 \%$ ee)

Scheme 33. Key steps of the second asymmetric synthesis of efavirenz 14.

Later, it was found that $(S)-\mathbf{1 3 5}$ behaves as a catalyst in the alkynylation step, which supersedes the use of $\mathrm{CF}_{3} \mathrm{CH}_{2} \mathrm{OH}$ and enables reducing the amounts of $\mathrm{ZnEt}_{2}$ and 132. These autocatalytic conditions generated $(S)-\mathbf{1 3 5}$ in a 79\% yield and with $99.6 \%$ ee. After correction for the initially added $(S)-\mathbf{1 3 5}$, the product was isolated in a yield of $67 \%$ and with an ee of $99.5 \%$ (Scheme 34) [131]. 


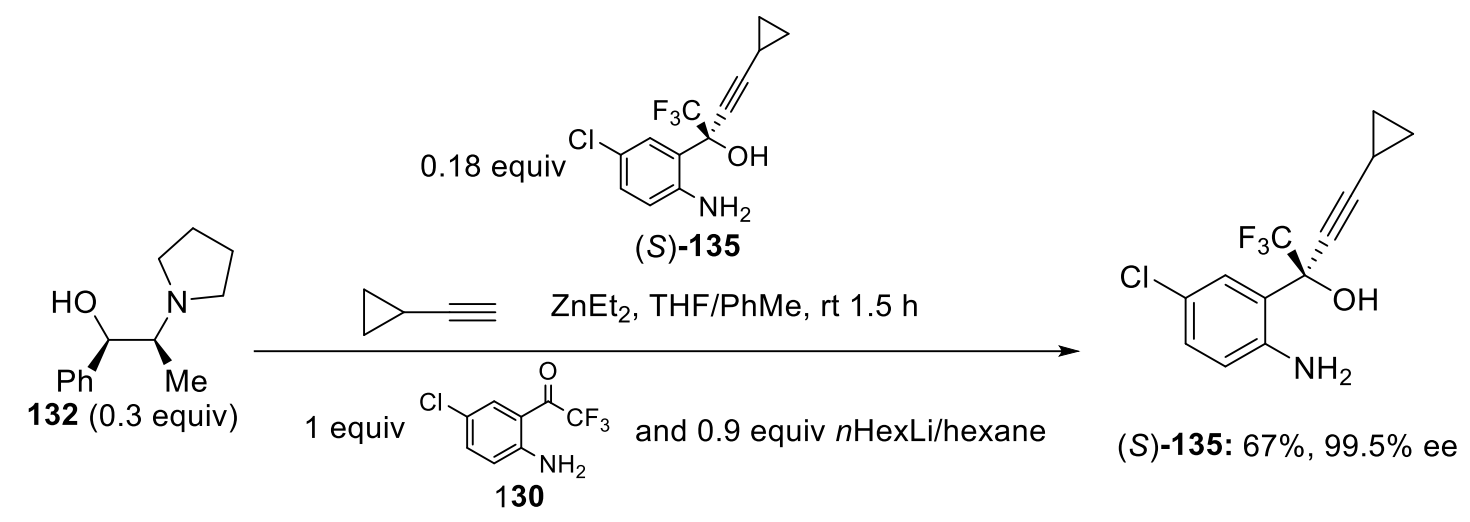

Scheme 34. Autocatalytic enantioselective alkynylation of ketone $\mathbf{1 3 0}$ in the synthesis of efavirenz

14.

Lonza patented an alternative synthetic pathway to efavirenez 14 in 2012, which does not require the $\mathrm{N}$-protection and deprotection steps or the use of phosgene. In the first step 1,4dichlorobenzene was transformed into ketone 139 (ortho-lithiation then quenching the carbanion with methyl trifluoroacetate). In the asymmetric version of the Lonza pathway (Scheme 35), addition of an organozinc reagent derived from 2-cyclopropylacetylene, to ketone $\mathbf{1 3 9}$ in the presence of chiral aminoalcohol derivative 140, proceeded with moderate enantioselectivity (46\%ee of $(S)$-141). In the racemic version of the pathway (not shown), 1-lithio-2-cyclopropylacetylene reacted with 139 to give $( \pm)-\mathbf{1 4 1}$ in $84 \%$ yield. Both routes continued by creation of a carbamate motif using chlorosulfonyl isocyanate, followed by heterocyclic ring closure via an Ullmann reaction. Naturally, the racemic pathway requires a resolution, while the asymmetric route gave efavirenz $(S)-\mathbf{1 4}$, but only at $45 \%$ ee [132]. 


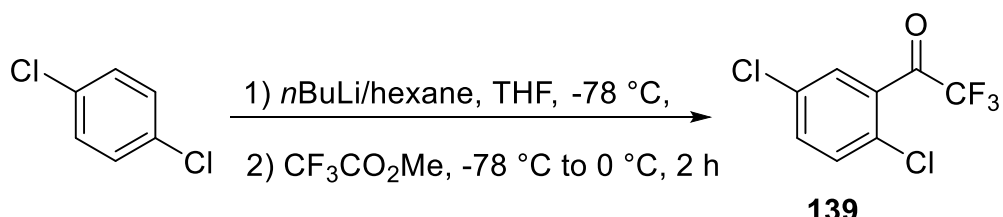<smiles>CC(NS(=O)(=O)c1cccc2ccccc12)C(O)(c1ccccc1)c1ccccc1</smiles>

140
1) $\mathrm{ZnMe}_{2}$ /heptane, PhMe, rt, $30 \mathrm{~min}$

2) $\triangleright \equiv \mathrm{rt}, 1.5 \mathrm{~h}$

3)

(139)

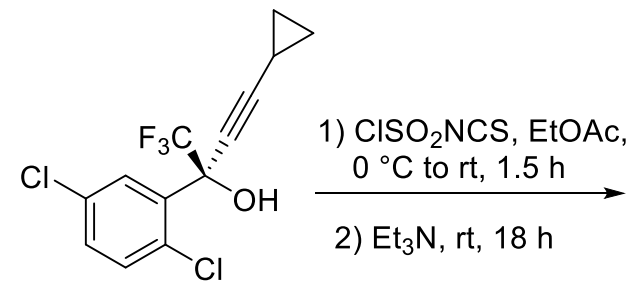

(S)-141 (46\% ee)<smiles>C[C@@](C#CC1CC1)(OC(N)=O)c1cc(Cl)ccc1Cl</smiles>

142 (46\% ee)
$\mathrm{K}_{3} \mathrm{PO}_{4}$, Cul, PhMe, $120^{\circ} \mathrm{C}, 24 \mathrm{~h}$ trans- $N, N$ '-dimethylcyclohexane-1,2-diamine

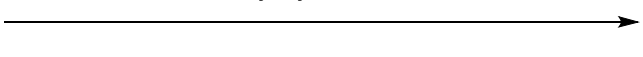

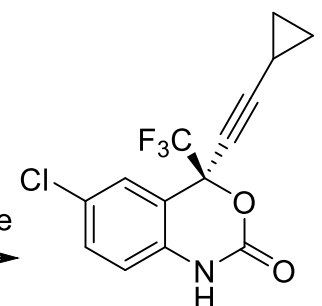

(S)-14 (45\% ee)

Scheme 35. The asymmetric version of the Lonza route to efavirenz 14.

In 2015, Correia et al. published a concise synthesis of racemic efavirenz 14 using flow technology. The first two steps followed the Lonza pathway but by replacing methyl trifluoroacetate with $N$-trifluoroacetyl morpholine. The morpholine byproduct can be removed in-line with an acidic scavenger column, whereas the alcohol byproduct cannot. Note that both classes of by-products interfere in the next step. The final step (Scheme 36) is remarkable since ( \pm )-141 was transformed into racemic efavirenz 14 in a single step ( $\mathrm{Cu}$-catalyzed $N$-aryl carbamate formation and cyclization). Since this step can also be performed under batch conditions, it may be possible to integrate it into other efavirenz syntheses [133]. 


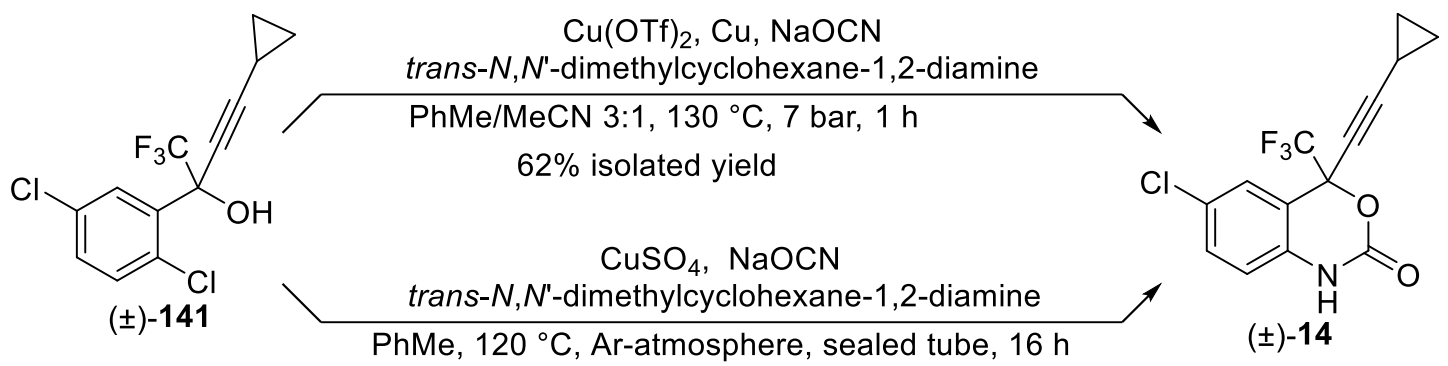

$62 \%$ NMR yield

Scheme 36. The last step in the flow synthesis of efavirenz 14 by Correia et al. .

A more recent synthesis was published in 2016. In this case instead of enantioselective alkynide addition, cinchona-catalyzed enantioselective trifluoromethylation was used to prepare tertiary alcohol $(S)-\mathbf{1 4 5}$ and Lonza intermediate $(S)$-141. The nitroaryl group of $(S)$-145 was readily reduced to aniline $(S)-\mathbf{1 3 5}$ and it was then transformed further into efavirenz $(S)$-14. The conditions described by Correia et al. [134] to transform intermediate $(S)-\mathbf{1 4 1}$ into efavirenz, were applied but without an argon atmosphere and sealed tube (Scheme 37). As a result only a $28 \%$ isolated yield was obtained (instead of a 62\% NMR yield) [134]. 

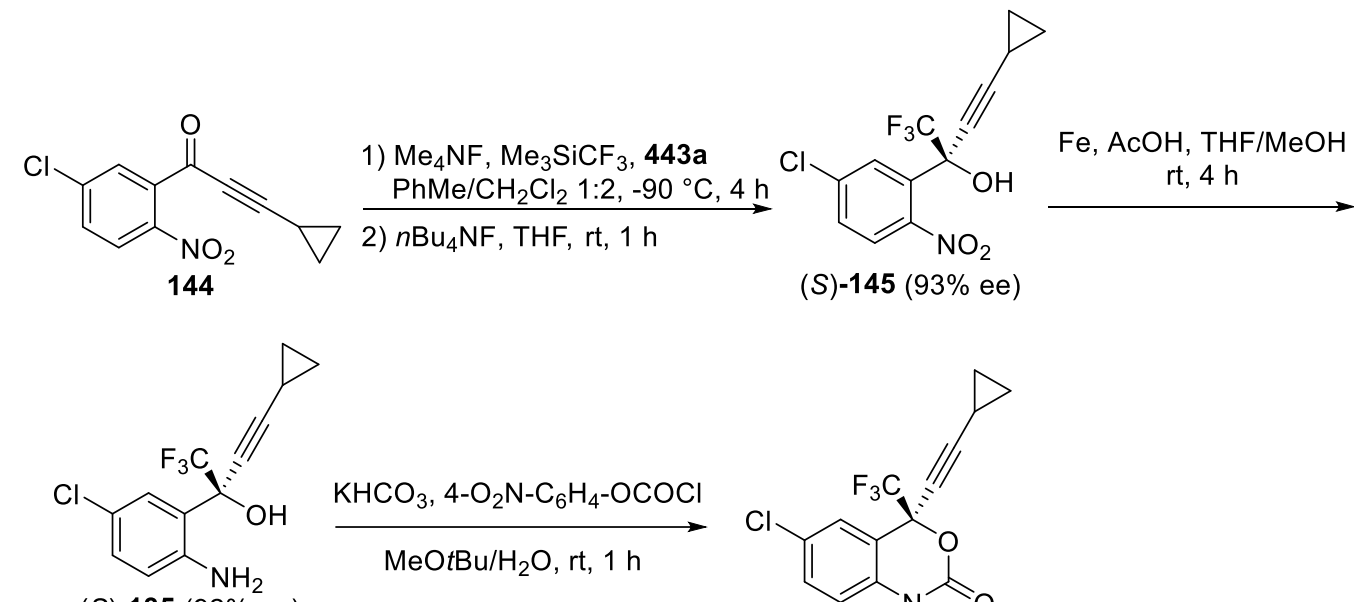<smiles>CC1(C#CC2CC2)OC(=O)Nc2ccc(Cl)cc21</smiles>

(S)-14 (91\% ee)<smiles>O=C(C#CC1CC1)c1cc(Cl)ccc1Cl</smiles>

146
1) $\mathrm{Me}_{4} \mathrm{NF}, \mathrm{Me}_{3} \mathrm{SiCF}_{3}, \mathbf{1 4 3 \mathrm { b }}$ $\mathrm{PhMe} / \mathrm{CH}_{2} \mathrm{Cl}_{2} 2: 1,-80^{\circ} \mathrm{C}, 4 \mathrm{~h}$

2) $n \mathrm{Bu}_{4} \mathrm{NF}, \mathrm{THF}, \mathrm{rt}, 1 \mathrm{~h}$<smiles>O[C@](C#CC1CC1)(c1cc(Cl)ccc1Cl)C(F)(F)F</smiles>

(S)-141 (91\% ee)

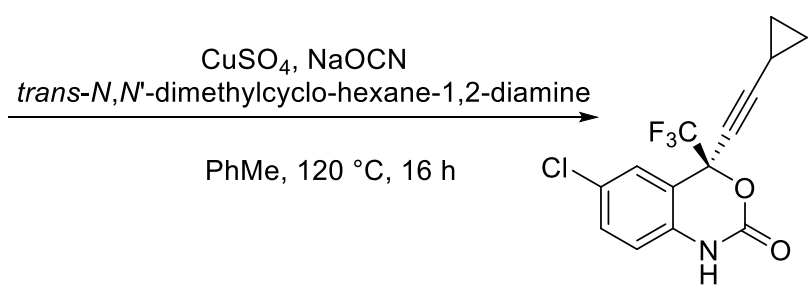

(S)-14 (90\% ee)

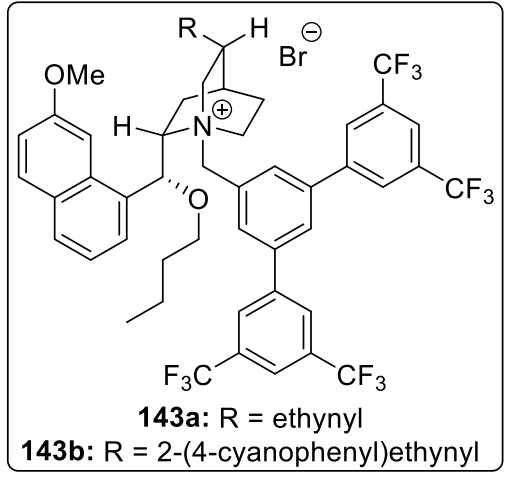

Scheme 37. Organocatalytic asymmetric synthesis of efavirenz 14.

The tertiary stereogenic center in efavirenz $\mathbf{1 4}$ is of the kind that is known to display a significant self-disproportionation of enantiomers (SDE) phenomenon via achiral chromatography [135] and sublimation [136]. One of the complications of the SDE is an erroneous determination of the stereochemical outcome of enantioselective catalytic reactions. However, this property was not discussed in above reactions. 


\section{Conclusions.}

Fluorine is embedded in medicinal chemistry culture as a tool for refining structure activity relationships of lead compound scaffolds and for modulating pharmacokinetic properties. As a consequence of such activity, which takes place with intensity during drug development programmes, an increasing number of new chemical entities are emerging each year and receiving approval that containing fluorine. It has gone from a rather rare modification in the 1950s to an unexceptional one in contemporary pharmaceuticals development.

It follows that there has been a notable broadening of interest in the development of new methods for the introduction of fluorine and fluorine containing motifs. Incorporating fluorine atoms can be costly particularly if scale up is required and thus a focus on process development and achieving efficient and environmentally satisfactory fluorination methods is currently among the most active fields in international organic chemistry at the moment. From the fluorine chemistry perspective innovation and focus has moved largely from materials and polymers to pharmaceuticals and bioactives over the last few decades.

This review has taken a rather narrow snapshot [137], focusing on the current top selling fluorine containing drugs in the last 2 or 3 years, but it aims to illustrate the extraordinarily high commercial returns that can be gained from successful drugs particularly during their patent lifetime. This is what drives the pharmaceuticals industry and the increasing relevance of fluorine in this enterprise is driving innovation in fluorine chemistry.

\section{Acknowledgments}

We gratefully acknowledges financial support from the National Natural Science Foundation of 
China (No. 21761132021), the Hungarian Research Foundation (NKFIH No. K 119282), and Ministry of Human Capacities, Hungary grant 20391-3/2018/FEKUSTRAT. The Qinlan Project of Jiangsu Province, and IKERBASQUE, the Basque Foundation for Science are also acknowledged.

\section{Literature.}

[1] (a) J. Fried, E.F. Sabo, Synthesis of 17 $\alpha$-hydroxycorticosterone and its $9 \alpha$-halo derivatives from 11-epi-17 $\alpha$-hydroxycorticosterone, J. Am. Chem. Soc. 75 (1953) 2273-2274;

(b) J. Fried, E.F. Sabo, 9 $\alpha$-Fluoro derivatives of cortisone and hydrocortisone. J. Am. Chem. Soc. 76 (1954) 1455-1456.

[2] (a) T. Fujiwara, D. O'Hagan, Successful fluorine-containing herbicide agrochemicals, J. Fluorine Chem, 167 (2014) 16-29;

(b) J. Han, A.E. Sorochinsky, T. Ono, V.A. Soloshonok, Biomimetic Transamination - a Metal-Free Alternative to the Reductive Amination. Application for Generalized Preparation of FluorineContaining Amines and Amino Acids, Curr. Org. Synth. 8 (2011) 281-294;

(c) Y. Zhu, J.L. Han, J. Wang, N. Shibata, M. Sodeoka, V.A. Soloshonok, J.A.S. Coelho, F.D. Toste, Modern Approaches for Asymmetric Construction of Carbon-Fluorine Quaternary Stereogenic Centers: Synthetic Challenges and Pharmaceutical Needs, Chem. Rev. 118 (2018) 3887-3964.

(d) Y. Ogawa, E. Tokunaga, O. Kobayashi, K. Hirai, N. Shibata, Current contributions of organofluorine compounds to the agrochemical industry, ISCIENCE 23 (2020) 101467. 
[3] (a) J. Wang, M. Sánchez-Roselló, J.L. Aceña, C. del Pozo, A.E. Sorochinsky, S. Fustero, V.A. Soloshonok, H. Liu, Fluorine in pharmaceutical industry: fluorine-containing drugs introduced to the market in the last decade (2001-2011), Chem. Rev. 114 (2014) 2432-2506;

(b) Y. Zhou, J. Wang, Z. Gu, S. Wang, W. Zhu, J.L. Aceña, V.A. Soloshonok, K. Izawa, H. Liu, Next Generation of Fluorine-Containing Pharmaceuticals, Compounds Currently in Phase II-III Clinical Trials of Major Pharmaceutical Companies: New Structural Trends and Therapeutic Areas, Chem. Rev. 116 (2016) 422-518.

(c) W. Zhu, J. Wang, S. Wang, Z. Gu, J.L. Aceña, K. Izawa, H. Liu, V.A. Soloshonok, Recent advances in the trifluoromethylation methodology and new $\mathrm{CF}_{3}$-containing drugs, J. Fluorine Chem. 167 (2014) 37-54.

(d) H. Mei, J. Han, K.D. Klika, K. Izawa, T. Sato, N.A. Meanwell, V.A. Soloshonok, Applications of fluorine-containing amino acids for drug design, Eur. J. Med. Chem. 186 (2020) 111826.

(e) N.A. Meanwell, Fluorine and fluorinated motifs in the design and application of bioisosteres for drug design, J. Med. Chem. 61 (2018) 5822-5880.

(f) H. Mei, J. Han, S. White, D.J. Graham, K. Izawa, T. Sato, S. Fustero, N.A. Meanwell, V.A. Soloshonok, Tailor-Made Amino Acids and Fluorinated Motifs as Prominent Traits in the Modern Pharmaceuticals, Chem. Eur. J. 26 (2020) 11349-11390.

(g) H. Mei, A.M. Remete, Y. Zou, H. Moriwaki, S. Fustero, L. Kiss, V.A. Soloshonok, J. Han, Fluorine-containing drugs approved by the FDA in 2019, Chin. Chem. Lett. (2020) https://doi.org/10.1016/j.cclet.2020.03.050. 
(h) Z. Yin, W. Hu, W. Zhang, H. Konno, K. Izawa, J. Han, V.A. Soloshonok, Tailor-made amino acid-derived pharmaceuticals approved by the FDA in 2019, Amino Acids (2020) https://doi.org/10.1007/s00726-020-02887-4.

(i) H. Mei, J. Han, S. Fustero, M. Mdeio-Simon, D.M. Sedgwick, C. Santi, R. Ruzziconi, V.A. Soloshonok, Fluorine-Containing Drugs Approved by the FDA in 2018, Chem. Eur. J. 25 (2019) 11797-11819.

[4] D. O'Hagan, Fluorine in health care: Organofluorine containing blockbuster drugs, J. Fluorine Chem. 131 (2010) 1071-1081.

[5] R.I. Fox, M.L. Herrmann, C.G. Frangou, G.M. Wahl, R.E. Morris, V. Strand, B.J. Kirschbaum, Mechanism of Action for Leflunomide in Rheumatoid Arthritis, Clin. Immunol. 93 (1999) 198208.

[6] R.R. Bartlett, M. Dimitrijevic, T. Mattar, T. Zielinski, T. Germann, E. Rüde, G.H. Thoenes, C.C.A. Küchle, H.-U. Schorlemmer, E. Bremer, A. Finnegan, R. Schleyerbach, Leflunomide (HWA 486), a novel immunomodulating compound for the treatment of autoimmune disorders and reactions leading to transplantation rejection, Agents Actions 32 (1991) 10-21.

[7] Q. Zhang, W.L. Pang, H. Chen, J. Cherrington, K. Lipson, L. Antonian, L.K. Shawver, Application of LC/MS/MS in the quantitation of SU101 and SU0020 uptake by 3T3/PDGFr cells, J. Pharm. Biomed. Anal. 28 (2002) 701-709.

[8] D. Alexander, B. Friedrich, T. Abruzzese, B. Gondolph-Zink, N. Wülker, W.K. Aicher, The Active form of Leflunomide, HMR1726, Facilitates TNF- $\alpha$ and IL-17 Induced MMP-1 and MMP-3 Expression, Cell. Physiol. Biochem. 17 (2006) 69-78. 
[9] (a) W.W Cao, P.N. Kao, A.C. Chao, P. Gardner, J. Ng, R.E. Morris, Mechanism of the Antiproliferative Action of Leflunomide. A77 1726, the Active Metabolite of Leflunomide, Does Not Block T-cell Receptor-Mediated Signal Transduction but Its Antiproliferative Effects Are Antagonized by Pyrimidine Nucleosides, J. Heart Lung Transplant. 14 (1995) 1016-1030;

(b) X. Xu, J.W. Williams, H. Gong, A. Finnegan, A. S-F. Chong, Two Activities of the Immunosuppressive Metabolite of Leflunomide, A77 1726. Inhibition of Pyrimidine Nucleotide Synthesis and Protein Tyrosine Phosphorylation, Biochem. Pharmacol. 52 (1996) 527-534;

(c) S.K. Manna, B.B. Aggarwal, Immunosuppressive Leflunomide Metabolite (A77 1726) Blocks TNF-Dependent Nuclear Factor-אB Activation and Gene Expression, J. Immunol. 162 (1999) 2095-2102.

(d) L.C. Hamilton, I. Vojnovic, T.D. Warner, A771726, the active metabolite of leflunomide, directly inhibits the activity of cyclo-oxygenase-2 in vitro and in vivo in a substrate-sensitive manner, Br. J. Pharmacol. 127 (1999) 1589-1596.

[10] (a) S.C. Tan, L.S. New, E.C.Y. Chan, Prevention of acetaminophen (APAP)-induced hepatotoxicity by leflunomide via inhibition of APAP biotransformation to N-acetyl-pbenzoquinone imine, Toxicol. Lett. 180 (2008) 174-181;

(b) G. McMahon, P.C. Tang, L.K. Shawver, K.P. Hirth, WO 1998052944A1 (1998).

[11] C. Warnke, G.M. zu Hörste, H.-P. Hartung, O. Stüve, B.C. Kieseier, Review of teriflunomide and its potential in the treatment of multiple sclerosis, Neuropsychiatr. Dis. Treat. 5 (2009) 333340.

[12] C. Papageorgiou, M. Zurini, H.-P. Weber, X. Borer, Leflunomide's Bioactive Metabolite Has the Minimal Structural Requirements for the Efficient Inhibition of Human Dihydroorotate 
Dehydrogenase, Bioorg. Chem. 25 (1997) 233-238.

[13] S. Ren, S.K. Wu, E.J. Lien, Dihydroorotate Dehydrogenase Inhibitors: Quantitative StructureActivity Relationship Analysis, Pharm. Res. 15 (1998) 286-295.

[14] S. Liu, E.A. Neidhardt, T.H. Grossman, T. Ocain, J. Clardy, Structures of human dihydroorotate dehydrogenase in complex with antiproliferative agents, Structure 8 (2000) 25-33.

[15] J. Jöckel, B. Wendt, M. Löffler, Structural and Functional Comparison of Agents Interfering with Dihydroorotate, Succinate and NADH Oxidation of Rat Liver Mitochondria, Biochem. Pharmacol. 56 (1998) 1053-1060.

[16] A. Prakash, B. Jarvis, Leflunomide. A Review of its Use in Active Rheumatoid Arthritis, Drugs 58 (1999) 1137-1164.

[17] K.P. Garnock-Jones, Teriflunomide: A Review of Its Use in Relapsing Multiple Sclerosis, CNS Drugs 27 (2013) 1103-1123.

[18] (a) C. Weber-Schoendorfer, E. Beck, T. Tissen-Diabaté, C. Schaefer, Leflunomide - A human teratogen? A still not answered question. An evaluation of the German Embryotox pharmacovigilance database, Reprod. Toxicol. 71 (2017) 101-107;

(b) J.B. Andersen, J.Y. Moberg, T. Spelman, M. Magyari, Pregnancy Outcomes in Men and Women Treated With Teriflunomide. A Population-Based Nationwide Danish Register Study, Front. Immunol. 9 (2018) 2706. doi: 10.3389/fimmu.2018.02706

[19] P. Baumann, S. Mandl-Weber, A. Völkl, C. Adam, I. Bumeder, F. Oduncu, R. Schmidmaier, Dihydroorotate dehydrogenase inhibitor A771726 (leflunomide) induces apoptosis and diminishes proliferation of multiple myeloma cells, Mol. Cancer Ther. 8 (2009) 366-375.

[20] O. Huang, W. Zhang, Q. Zhi, X. Xue, H. Liu, D. Shen, M. Geng, Z. Xie, M. Jiang, 
Teriflunomide, an immunomodulatory drug, exerts anticancer activity in triple negative breast cancer cells, Exp. Biol. Med. (Maywood) 240 (2015) 426-437.

[21] G. Qiao, L. Yang, Z. Li, J.W. Williams, J. Zhang, A77 1726, the active metabolite of leflunomide, attenuates lupus nephritis by promoting the development of regulatory $\mathrm{T}$ cells and inhibiting IL-17-producing double negative T cells, Clin. Immunol. 157 (2015) 166-174.

[22] S. Kota, V. Tellapaneni, S. Duddu, K.S.B.R. Adibhatla, V.C. Nannapaneni, WO 2017103942 A1 (2017).

[23] K.P. Hirth, D.P. Schwartz, E. Mann, L.K. Shawver, G. Kéri, I. Székely, T. Bajor, K. Haimichael, L. Örfi, A. Levitzki, A. Gazit, A. Ullrich, R. Lammers, F.F. Kabbinavar, D.J. Slamon, C.P. Tang, WO 1995019169A2 (1995).

[24] S. Patel, S. Dhol, V. Ray, WO 2014177978A2 (2014).

[25] J. Hachtel, B. Neises, W. Schwab, R. Utz, M. Zahn, US 20040186173A1 (2004).

[26] K. Deo, S. Patel, S. Dhol, S. Sanghani, V. Ray, WO 2009147624A2 (2009).

[27] R.R. Bartlett, K.U. Weithmann, E.S. Kurtz, US 5504084 (1996).

[28] S. T. Rajan, S. Eswaraiah, WO 2015029063A2 (2015).

[29] (a) T.-X. Métro, J. Bonnamour, T. Reidon, A. Duprez, J. Sarpoulet, J. Martinez, F. Lamaty, Comprehensive Study of the Organic-Solvent-Free CDI-Mediated Acylation of Various Nucleophiles by Mechanochemistry, Chem. Eur. J. 21 (2015) 12787-12796.

(b) T.-X. Métro, J. Bonnamour, T. Reidon, J. Sarpoulet, J. Martinez, F. Lamaty, Mechanosynthesis of amides in the total absence of organic solvent from reaction to product recovery, Chem. Commun. 48 (2012) 11781-11783.

[30] D. Kim, L. Wang, M. Beconi, G.J. Eiermann, M.H. Fisher, H. He, G.J. Hickey, J.E. Kowalchick, 
B. Leiting, K. Lyons, F. Marsilio, M.E. McCann, R.A. Patel, A. Petrov, G. Scapin, S.B. Patel, R.S. Roy, J.K. Wu, M.J. Wyvratt, B.B. Zhang, L. Zhu, N.A. Thornberry, A.E. Weber, (2R)-4-Oxo-4-[3(Trifluoromethyl)-5,6-dihydro[1,2,4]triazolo[4,3-a]pyrazin-7(8H)-yl]-1-(2,4,5-

trifluorophenyl)butan-2-amine: A Potent, Orally ActiveDipeptidyl Peptidase IV Inhibitor for the Treatment of Type 2 Diabetes, J. Med. Chem. 48 (2005) 141-151.

[31] S. Dhillon, Sitagliptin, Drugs 70 (2010) 489-512.

[32] K.B. Hansen, J. Balsells, S. Dreher, Y. Hsiao, M. Kubryk, M. Palucki, N. Rivera, D. Steinhuebel, J.D. Armstrong III, D. Askin, E.J.J. Grabowski, First Generation Process for the Preparation of the DPP-IV Inhibitor Sitagliptin, Org. Process Res. Dev. 9 (2005) 634-639.

[33] (a) S. Zhou, J. Wang, X. Chen, J.L. Aceña, V.A. Soloshonok, H. Liu, Chemical Kinetic Resolution of Unprotected $\beta$-Substituted- $\beta$-Amino Acids Using Recyclable Chiral Ligands, Angew. Chem. Int. Ed. 53 (2014) 7883-7886;

(b) S. Zhou, S. Wang, J. Wang, Y. Nian, P. Peng, V. A. Soloshonok, H. Liu, Configurationally Stable (S)- and (R)-a-Methylproline-Derived Ligands for the Direct Chemical Resolution of Free Unprotected $\beta^{3}$-Amino Acids, Eur. J. Org. Chem. 2018 (2018) 1821-1832.

[34] V.A. Soloshonok, A. Wzorek, K.D. Klika, A question of policy: should tests for the selfdisproportionation of enantiomers (SDE) be mandatory for reports involving scalemates? Tetrahedron: Asymmetry 28 (2017) 1430-1434.

[35] Sorochinsky, A. E.; Aceña, J. L.; Soloshonok, V. A. Self-Disproportionation of Enantiomers of Chiral, Non-Racemic Fluoroorganic Compounds: Role of Fluorine as Enabling Element, Synthesis 45 (2013) 141-152.

[36] G.M. Keating, A. Vaidya, Sofosbuvir: First Global Approval, Drugs 74 (2014) 273-282. 
[37] J.P. Parrish, S.K. Lee, C.G. Boojamra, H. Hui, D. Babusis, B. Brown, H. Shih, J.Y. Feng, A.S.

Ray, R.L. Mackman, Evaluation of 2'- $\alpha$-fluorine modified nucleoside phosphonates as potential inhibitors of HCV polymerase, Bioorg. Med. Chem. Lett. 23 (2013) 3354-3357.

[38] G.M. Keating, Ledipasvir/Sofosbuvir: A Review of Its Use in Chronic Hepatitis C, Drugs 75 (2015) 675-685.

[39] S.L. Greig, Sofosbuvir/Velpatasvir: A Review in Chronic Hepatitis C, Drugs 76 (2016) 15671578.

[40] P. Chen, S. Peng, Y. Li, D. Li, X. Dong, Process for preparation of lactone derivatives and intermediates thereof, (2018) WO2018032356.

[41] E. Cini, G. Barreca, L. Carcone, F. Manetti, M. Rasparini, M. Taddei, Stereoselective Synthesis of Sofosbuvir through Nucleoside Phosphorylation Controlled by Kinetic Resolution, Eur. J. Org. Chem. 2018 (2018) 2622-2628.

[42] L. Citrome, Paliperidone: quo vadis?, Int. J. Clin. Pract. 61 (2007) 653-662.

[43] M.K.J. François, R.C.A. Embrechts, H.K. Borghijs, J. Monbaliu, WO 1997044039A1 (1997).

[44] E. Spina, R. Cavallaro, The pharmacology and safety of paliperidone extended-release in the treatment of schizophrenia, Expert Opin. Drug Saf. 6 (2007) 651-662.

[45] M.N. Samtani, A. Vermeulen, K. Stuyckens, Population Pharmacokinetics of Intramuscular Paliperidone Palmitate in Patients with Schizophrenia. A Novel Once-Monthly, Long-Acting Formulation of an Atypical Antipsychotic, Clin. Pharmacokinet. 48 (2009) 585-600.

[46] M.K.J. François, W.M.A.C. Dries, E.D.G. Basstanie, WO 199925354A2 (1999). 
[47] B. Dolitzky, WO 2008024415A2 (2008).

[48] J.R.R. Ravi, M.P. Reddy, B.R.A.K. Satya, N.V. Chowdary, WO 2009010988A1 (2009).

[49] J. Bartl, F. Picha, WO 2009015828A1 (2009).

[50] J.R.R. Ravi, M.P. Reddy, B.R.A.K. Satya, N.V. Chowdary, WO 2009016653A1 (2009).

[51] R.N. Kankan, D.R. Rao, S.L. Pathi, WO 2009047499A2 (2009).

[52] A.A. Chavan, A.V. Joshi, M.N. Bhanu, WO 2009116071A2 (2009).

[53] U.R. Bapat, M. Jayamani, S. Ravisaravanan, V.A. Sodha, J. Valgeirsson, WO 2009118655A2 (2009).

[54] J.P. Koilpillai, P.B. Kulkarni, L.M. Kelkar, S.A. Kale, S.G. Potdar, K.B. Narwade, M.A. Khan, J.R. Thorat, WO 2009130710A2 (2009).

[55] M.S. Reddy, S. Eswaraiah, R. Satyanarayana, WO 2010004578A2 (2010).

[56] I.A. Modi, K.R. Sodagar, M. Vineet, S.H. Jain, S.N. Parikh, A.O. Sharma, U.R. Bapat, B.M. Khamar, WO 2010064134A2 (2010).

[57] M. Ružič, A. Pecavar, D. Prudic, I. Plaper, A. Klobcar, WO 2011006638A1 (2011).

[58] G. Dixit, A.S. Khile, J.L. Patel, N.S. Pradhan, WO 2011030224A2 (2011).

[59] A.A. Chavan, M.N. Bhanu, A.V. Joshi, WO 2012134445A1 (2012).

[60] P.V. Solanki, S.B. Uppelli, B.S. Pandit, V.T. Mathad, An Improved and Efficient Process for the Production of Highly Pure Paliperidone, a Psychotropic Agent, via DBU Catalyzed N-Alkylation, ACS Sustainable Chem. Eng. 1 (2013) 243-248.

[61] R. Riva, L. Banfi, G. Castaldi, D. Ghislieri, L. Malpezzi, F. Musumeci, R. Tufaro, M. Rasparini, Selective Chemical Oxidation of Risperidone: A Straightforward and Cost-Effective Synthesis of Paliperidone, Eur. J. Org. Chem. (2011) 2319-2325. 
[62] S. Ini, Y. ShmuelyO. Porter-Kleks, K. Chen, E. Lancry, C. Singer, WO 2009089076A2 (2009).

[63] M Gharpure, D. Rane, H.M.V. Swamy, P. Patil, J. Thorat, WO 2013046225A2 (2013).

[64] K. Rajiv, K.A.P. Dharmesh, S.M. Dattaray, R.S. Praveen, P.P. Prashant, V.P. Santosh, WO 2011074017A1 (2011).

[65] D. R. Rao, R. Ponnaiah, P.K. Neela, G. Batthini, T.V. Narasimharao, K. Ravanababu, K. Sudheer, WO 2012164582A1 (2012).

[66] Y.N. Lamb, Glecaprevir/Pibrentasvir: First Global Approval, 77 (2017) 1797-1804.

[67] R. Wagner, J.T. Randolph, S.V. Patel, L. Nelson, M.A. Matulenko, R. Keddy, J.K. Pratt, D. Liu, A.C. Krueger, P.L. Donner, D.K. Hutchinson, C. Flentge, D. Betebenner, T. Rockway, C.J. Maring, T.I. Ng, P. Krishnan, T. Pilot-Matias, C. Collins, N. Panchal, T. Reisch, T. Dekhtyar, R. Mondal, D.F. Stolarik, Y. Gao, W. Gao, D.A. Beno, W.M. Kati, Highlights of the Structure-Activity Relationships of BenzimidazoleLinked Pyrrolidines Leading to the Discovery of the Hepatitis C Virus NS5A Inhibitor Pibrentasvir (ABT-530), J. Med. Chem. 61 (2018) 4052-4066.

[68] J. Koerts, A.E.M.F. Soffers, J. Vervoort, A. De Jager, I.M.C.M. Rietjens, Occurrence of the NIH Shift Upon the Cytochrome P450-Catalyzed in Vivo and in Vitro Aromatic Ring Hydroxylation of Fluorobenzenes, Chem. Res. Toxicol. 11 (1998) 503-512.

[69] R.D. Cink, K.A. Lukin, R.D. Bishop, G. Zhao, M.J. Pelc, T.B. Towne, B.D. Gates, M.M. Ravn, D.R. Hill, C. Ding, S.C. Cullen, J. Mei, M.R. Leanna, J. Henle, J.G. Napolitano, N.K. Nere, S. Chen, A. Sheikh, J.M. Kallemeyn, Development of the Enabling Route for Glecaprevir via Ring-Closing Metathesis, Org. Process Res. Dev. 24 (2020) 183-200.

[70] (a) A. Kawashima, C. Xie, H, Mei, R. Takeda, A. Kawamura, T. Sato, H. Moriwaki, K. Izawa, 
J. Han, J.L. Aceña, V.A. Soloshonok, Asymmetric synthesis of (1R,2S)-1-amino-2vinylcyclopropanecarboxylic acid by sequential $\mathrm{S}_{\mathrm{N}} 2-\mathrm{S}_{\mathrm{N}} 2$ ' dialkylation of (R)-N-(benzyl)prolinederived glycine Schiff base Ni(II) complex, RSC Adv. 5 (2015) 1051-1058;

(b) T. Sato, K. Izawa, J.L. Aceña, H. Liu, V.A. Soloshonok, Tailor-Made $\alpha$-Amino Acids in Pharmaceutical Industry: Synthetic Approaches to (1R,2S)-1-Amino-2-vinylcyclopropane-1carboxylic Acid (Vinyl-ACCA), Eur. J. Org. Chem. 2016 (2016) 2757-2774;

(c) A. Kawashima, S. Shu, R. Takeda, A. Kawamura, T. Sato, H. Moriwaki, J. Wang, K. Izawa, J.L. Aceña, V.A. Soloshonok, H. Liu, Advanced asymmetric synthesis of (1R,2S)-1-amino-2vinylcyclopropanecarboxylic acid by alkylation/cyclization of newly designed axially chiral $\mathrm{Ni}(\mathrm{II})$ complex of glycine Schiff base, Amino Acids 48 (2016) 973-986.

[71] O.M. Klibanov, Elvitegravir, an oral HIV integrase inhibitor, for the potential treatment of HIV infection, Curr. Opin. Investig. Drugs 10 (2009) 190-200.

[72] E.D. Deeks, Elvitegravir: a review of its use in adults with HIV-1 infection, Drugs 74 (2014) $687-697$.

[73] M. Shiomi, S. Matsuki, A. Ikeda, T. Ishikawa, N. Nishino, M. Kimura, Y. Kumagai, S. Irie, Pharmacokinetic and bioequivalence evaluation of single-tablet and separate-tablet regimens for once-daily cobicistat-boosted elvitegravir in healthy Japanese male subjects: A randomized, two-way crossover study, Clin. Pharmacol. Drug Dev. 4 (2015) 218-225.

[74] N.R. Unger, M.V. Worley, J.J. Kisgen, E.M. Sherman, L.M. Childs-Kean, Elvitegravir for the treatment of HIV, Expert Opin. Pharmacother. 17 (2016) 2359-2370.

[75] K. Shimura, E.N. Kodama, Elvitegravir: a new HIV integrase inhibitor, Antivir. Chem. Chemother. 20 (2009) 79-85. 
[76] K. Shimura, E. Kodama, Y. Sakagami, Y. Matsuzaki, W. Watanabe, K. Yamataka, Y. Watanabe, Y. Ohata, S. Doi, M. Sato, M. Kano, S. Ikeda, M. Matsuoka, Human cell proteins and human immunodeficiency virus DNA integration, J. Virol. 82 (2008) 764-774.

[77] F. Turlure, E. Devroe, P.A. Silver, A. Engelman, Human cell proteins and human immunodeficiency virus DNA integration, Front. Biosci. 9 (2004) 3187.

[78] N. Vandegraaff, A. Engelman, Molecular mechanisms of HIV integration and therapeutic intervention, Expert Rev. Mol. Med. 9 (2007) 1-19.

[79] W. Yang, T.A. Steitz, Recombining the structures of HIV integrase, RuvC and RNase H, Structure 3 (1995) 131-134.

[80] T. Kawasuji, B. A. Johns, H. Yoshida, J. G. Weatherhead, T. Akiyama, T. Taishi, Y. Taoda, M. Mikamiyama-Iwata, H. Murai, R. Kiyama, M. Fuji, N. Tanimoto, T. Yoshinaga, T. Seki, M. Kobayashi, A. Sato, E. P. Garvey, T. Fujiwara, Carbamoyl pyridone HIV-1 integrase inhibitors. 2. Bi-and tricyclic derivatives result in superior antiviral and pharmacokinetic profiles, J. Med. Chem. 56 (2013) 1124-1135.

[81] J. Marinello, C. Marchand, B.T. Mott, A. Bain, C.J. Thomas, Y. Pommier, Comparison of raltegravir and elvitegravir on HIV-1 integrase catalytic reactions and on a series of drugresistant integrase mutants, Biochemistry. 47 (2008) 9345-9354.

[82] T. Kawasuji, M. Fuji, T. Yoshinaga, A. Sato, T. Fujiwara, R. Kiyama, A platform for designing HIV integrase inhibitors. Part 2: a two-metal binding model as a potential mechanism of HIV integrase inhibitors, Bioorg. Med. Chem. 14 (2006) 8420-8429.

[83] S. Rádl, J. Stach, O. Píša, J. Cinibulk, J. Havlíček, M. Zajícová, T. Pekárek, An improved synthesis of elvitegravir, J. Heterocycl. Chem. 53 (2016) 1738-1749. 
[84] M. Sato, T. Motomura, H. Aramaki, T. Matsuda, M. Yamashita, Y. Ito, H. Kawakami, Y. Matsuzaki, W. Watanabe, K. Yamataka, S. Ikeda, E. Kodama, M. Matsuoka, H. Shinkai, Novel HIV-1 integrase inhibitors derived from quinolone antibiotics, J. Med. Chem. 49 (2006) 1506-1508.

[85] C.L. Sawyers, M.E. Jung, C.D. Chen, S. Ouk, D. Welsbie, C. Tran, J. Wongvipat, D. Yoo, WO2006124118A1 (2006).

[86] S. Flanders, B. Brown, M. Massoudi, N. Schultz, K. Ramaswamy, Corrected Net Health Benefit Calculations for Enzalutamide Using ASCO Value Framework Guidelines and NCCN Evidence Blocks, J. Manag. Care Spec. Pharm. 23 (2017) 1202.

[87] E. Nevedomskaya, S.J. Baumgart, B. Haendler, Recent Advances in Prostate Cancer Treatment and Drug Discovery, Int. J. Mol. Sci. 19 (2018) 1359.

[88] C.N. Sternberg, Enzalutamide, an oral androgen receptor inhibitor for treatment of castrationresistant prostate cancer, Future Oncol. 15 (2019) 1437-1457.

[89] T.S. Vasaitis, V.C.O. Njar, Novel, potent anti-androgens of therapeutic potential: recent advances and promising developments, Future Med. Chem. 2 (2010) 667-680.

[90] C.E. Bohl, D.D. Miller, J. Chen, C.E. Bell, J.T. Dalton, Structural Basis for Accommodation of Nonsteroidal Ligands in the Androgen Receptor, J. Biol. Chem. 280 (2005) 37747-37754.

[91] M.E. Jung, S. Ouk, D. Yoo, C.L. Sawyers, C. Chen, C. Tran, J. Wongvipat, Structure-Activity Relationship for Thiohydantoin Androgen Receptor Antagonists for Castration-Resistant Prostate Cancer (CRPC), J. Med. Chem. 53 (2010) 2779-2796.

[92] A. Thompson, C. Lamberson, S. Greenfield, WO2011106570A1 (2011).

[93] J. Stach, O. Klecan, P. Lehnert, J. Rymes, WO2015154730A1 (2015). 
[94] S. Frigoli, D. Longoni, M. Alpegiani, WO2016188996A1 (2016).

[95] Inventors: K.R. Chivukula, V.V.R. Karuturi, S. Benda, R. Anke, D. Gajula, V.R.K.M. Moturu, V.S.K. Indukuri, S.R.A. Gorantla, S. Chava, WO2016051423A2 (2016).

[96] P.H. Desai, S. Seetharaman, V.H. Nikam, K.M. Kamble, WO2019106691A1 (2019).

[97] E.P. Garvey, B.A. Johns, M.J. Gartland, S.A. Foster, W.H. Miller, R.G. Ferris, R.J. Hazen, M.R. Underwood, E.E. Boros, J.B. Thompson, J.G. Weatherhead, C.S. Koble, S.H. Allen, L.T. Schaller, R.G. Sherrill, T. Yoshinaga, M. Kobayashi, C. Wakasa-Morimoto, S. Miki, K. Nakahara, T. Noshi, A. Sato, T. Fujiwara, The naphthyridinone GSK364735 is a novel, potent human immunodeficiency virus type 1 integrase inhibitor and antiretroviral, Antimicrob. Agents Chemother. 52 (2008) 901-908.

[98] R.E. Ziegler, B.K. Desai, J.A. Jee, B.F. Gupton, T.D. Roper, T.F. Jamison, 7 - Step Flow Synthesis of the HIV Integrase Inhibitor Dolutegravir, Angew. Chem. Int. Ed. 57 (2018) $7181-7185$.

[99] M. Kobayashi, T. Yoshinaga, T. Seki, C. Wakasa-Morimoto, K.W. Brown, R. Ferris, S.A. Foster, R.J. Hazen, S. Miki, A. Suyama-Kagitani, S. Kawauchi-Miki, T. Taishi, T. Kawasuji, B.A. Johns, M.R. Underwood, E.P. Garvey, A. Sato, T. Fujiwara, In vitro antiretroviral properties of S/GSK1349572, a next-generation HIV integrase inhibitor, Antimicrob. Agents Chemother. 55 (2011) 813-821.

[100] C.E. Kandel, S.L. Walmsley, Dolutegravir-a review of the pharmacology, efficacy, and safety in the treatment of HIV, Drug Des. Devel. Ther. 9 (2015) 3547-3555.

[101] M.L. Cottrell, T. Hadzic, A.D.M. Kashuba, Clinical pharmacokinetic, pharmacodynamic and drug-interaction profile of the integrase inhibitor dolutegravir, Clin. Pharmacokinet. 52 
(2013) 981-994.

[102] J.M. Llibre, F. Pulido, F. García, M. García Deltoro, J.L. Blanco, R. Delgado, Genetic barrier to resistance for dolutegravir, AIDS Rev. 17 (2015) 56-64.

[103] A.D. Ballantyne, C.M. Perry, Dolutegravir: first global approval, Drugs 73 (2013) 1627-1637.

[104] S.L. Greig, E.D. Deeks, Abacavir/dolutegravir/lamivudine single-tablet regimen: a review of its use in HIV-1 infection, Drugs 75 (2015) 503-514.

[105] S. Castellino, L. Moss, D. Wagner, J. Borland, I. Song, S. Chen, Y. Lou, S.S. Min, I. Goljer, A. Culp, S.C. Piscitelli, P.M. Savina, Metabolism, excretion, and mass balance of the HIV1 integrase inhibitor dolutegravir in humans, Antimicrob. Agents Chemother. 57 (2013) $3536-3546$

[106] R.C. Rathbun, S.M. Lockhart, M.M. Miller, M.D. Liedtke, Dolutegravir, a second-generation integrase inhibitor for the treatment of HIV-1 infection, Ann. Pharmacother. 48 (2014) 395403.

[107] S. Sankareswaran, M. Mannam, V. Chakka, S.R. Mandapati, P. Kumar, Identification and control of critical process impurities: an improved process for the preparation of dolutegravir sodium, Org. Process Res. Dev. 20 (2016) 1461-1468.

[108] D.L. Hughes, Review of synthetic routes and final forms of integrase inhibitors dolutegravir, cabotegravir, and bictegravir, Org. Process Res. Dev. 23 (2019) 716-729.

[109] A. Markham, Bictegravir: first global approval, Drugs 78 (2018) 601-606.

[110] (a) J. Gallant, A. Lazzarin, A. Mills, C. Orkin, D. Podzamczer, P. Tebas, P.M. Girard, I. Brar, E.S. Daar, D. Wohl, J. Rockstroh, X. Wei, J. Custodio, K. White, H. Martin, A. Cheng, E. Quirk, Bictegravir, emtricitabine, and tenofovir alafenamide versus dolutegravir, abacavir, 
and lamivudine for initial treatment of HIV-1 infection (GS-US-380-1489): a double-blind, multicentre, phase 3, randomised controlled non-inferiority trial, Lancet 390 (2017) 20632072;

(b) P.E. Sax, E. DeJesus, G. Crofoot, D. Ward, P. Benson, R. Dretler, A. Mills, C. Brinson, J. Peloquin, X. Wei, K. White, A. Cheng, H. Martin, E. Quirk, Bictegravir versus dolutegravir, each with emtricitabine and tenofovir alafenamide, for initial treatment of HIV-1 infection: a randomised, double-blind, phase 2 trial, Lancet HIV 4 (2017) 154-160.

(c) M. Oliveira, R.I. Ibanescu, K. Anstett, T. Mésplède, J.P. Routy, M.A. Robbins, B.G. Brenner, Selective resistance profiles emerging in patient-derived clinical isolates with cabotegravir, bictegravir, dolutegravir, and elvitegravir, Retrovirology 15 (2018) 56.

[111] E.D. Deeks, Bictegravir/emtricitabine/tenofovir alafenamide: a review in HIV-1 infection, Drugs 78 (2018) 1817-1828.

[112] M. Tsiang, G.S. Jones, J. Goldsmith, A. Mulato, D. Hansen, E. Kan, L. Tsai, R.A. Bam, G. Stepan, K.M. Stray, A. Niedziela-Majka, S.R. Yant, H. Yu, G. Kukolj, T. Cihlar, S. Lazerwith, K.L. White, H. Jin, Antiviral activity of bictegravir (GS-9883), a novel potent HIV-1 integrase strand transfer inhibitor with an improved resistance profile, Antimicrob. Agents Chemother. 60 (2016) 7086-7097.

[113] S.J. Smith, X.Z. Zhao, T.R. Burke, S.H. Hughes, Efficacies of cabotegravir and bictegravir against drug-resistant HIV-1 integrase mutants, Retrovirology 15 (2018) 37

[114] L.S. Jeong, R.F. Schinazi, J.W. Beach, H.O. Kim, S. Nampalli, K. Shanmuganathan, A.J. Alves, A. McMillan, C.K. Chu, R. Mathis, Asymmetric Synthesis and Biological Evaluation of $\beta$-L-

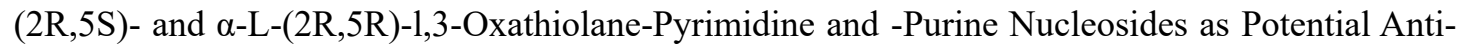


HIV Agents, J. Med. Chem. 36 (1993) 181-195.

[115] S. Rama, S.C.S. Gorantla, L.R. Vadali, V.B.K.S. Inupakutika, S.R. Dasari, N. Mittapelly, S.K.

Singh, D. Datta, Novel process for the preparation of cis-nucleoside derivative, WO2011095987 (2011).

[116] A.P. Osborne, D. Brick, G. Ruecroft, I.N. Taylor, Immobilization of Cholesterol Esterase for Use in Multiple Batch Biotransformations to Prepare (-)- FTC (Emtricitabine), Org. Process Res. Dev. 10 (2006) 670-672.

[117] M. Yasumoto, H. Ueki, T. Ono, T. Katagiri, V.A. Soloshonok, Self-Disproportionation of Enantiomers via Sublimation: Isopropyl 3,3,3-(Trifluoro)-Lactate, J. Fluorine Chem. 131 (2010) $535-539$.

[118] T. Nakamura, K. Tateishi, S. Tsukagoshi, S. Hashimoto, S. Watanabe, V.A. Soloshonok, J.L. Aceña, O. Kitagawa, Self-Disproportionation of Enantiomers of Non-racemic Chiral Amine Derivatives Through Achiral Chromatography, Tetrahedron 68 (2012) 4013-4017.

[119] S.D. Young, S.F. Britcher, L.S. Payne, L.O. Tran, W.C. Lumma Jr., WO1994003440 (1994).

[120] E.J.J. Grabowski, Enantiopure Drug Synthesis: From Methyldopa to Imipenem to Efavirenz, Chirality 17 (2005) S249-S259.

[121] S.M.E. Vrouenraets, F.W.N.M. Wit, J. Van Tongeren, J.M.A. Lange, Efavirenz: a review, Expert Opin. Pharmacother., 8 (2007) 851-871.

[122] E. De Clerq, The Nucleoside Reverse Transcriptase Inhibitors, Nonnucleoside Reverse Transcriptase Inhibitors, and Protease Inhibitors in the Treatment of HIV Infections (AIDS), in: 
E. De Clerq (Ed.) Advances in Pharmacology, Vol. 67: Antiviral Agents, Elsevier, Amsterdam, 2013, pp. 317-358.

[123] G. Pastuch-Gawołek, D. Gillner, E. Król, K. Walczak, I. Wandzik, Selected nucleos(t)idebased prescribed drugs and their multi-target activity, Eur. J. Pharmacol. 865 (2019) 172747.

[124] W.E. Johnson, Origins and evolutionary consequences of ancient endogenous retroviruses, Nat. Rev. Microbiol. 17 (2019) 355-370.

[125] S. Purser, P.R. Moore, S. Swallow, V. Gouverneur, Fluorine in medicinal chemistry, Chem. Soc. Rev. 37 (2008) 320-330.

[126] S.D. Young, S.F. Britcher, L.O. Tran, L.S. Payne, W.C. Lumma, T.A. Lyle, J.R. Huff, P.S. Anderson, D.B. Olsen, S.S. Carroll, D.J. Pettibone, J.A. O’Brien, R.G. Ball, S.K. Balani, J.H. Lin, I-W. Chen, W.A. Schleif, V.V. Sardana, W.J. Long, V.W. Byrnes, E.A. Emini, L-743,726 (DMP-266): a novel, highly potent nonnucleoside inhibitor of the human immunodeficiency virus type 1 reverse transcriptase, Antimicrob. Agents Chemother. 39 (1995) 2602-2605.

[127] L.A. Radesca, Y.S. Lo, J.R. Moore, M.E. Pierce, Synthesis of HIV-1 reverse transcriptase inhibitor DMP 266, Synth. Commun. 27 (1997) 4373-4384.

[128] A.S. Thompson, E.G. Corley, M.F. Huntington, E.J.J. Grabowski, Use of an ephedrine alkoxide to mediate enantioselective addition of an acetylide to a prochiral ketone: asymmetric synthesis of the reverse transcriptase inhibitor L-743,726, Tetrahedron Lett. 36 (1995) 89378940.

[129] M.E. Pierce, R.L. Parsons Jr., L.A. Radesca, Y.S. Lo, S. Silverman, J.R. Moore, Q. Islam, A. Choudhury, J.M.D. Fortunak, D. Nguyen, C. Luo, S.J. Morgan, W.P. Davis, P.N. Confalone, C.y. Chen, R.D. Tillyer, L. Frey, L. Tan, F. Xu, D. Zhao, A.S. Thompson, E.G. Corley, E.J.J. 
Grabowski, R. Reamer, P.J. Reider, Practical Asymmetric Synthesis of Efavirenz (DMP 266), an HIV-1 Reverse Transcriptase Inhibitor, J. Org. Chem. 63 (1998) 8536-8543.

[130] L. Tan, C.-y. Chen, R.D. Tillyer, E.J.J. Grabowski, P.J. Reider, A Novel, Highly Enantioselective Ketone Alkynylation Reaction Mediated by Chiral Zinc Aminoalkoxides, Angew. Chem. Int. Ed. 38 (1999) 711-713.

[131] N. Chinkov, A. Warm, E.M. Carreira, Asymmetric Autocatalysis Enables an Improved Synthesis of Efavirenz, Angew. Chem. Int. Ed. 50 (2011) 2957-2961.

[132] D. Dai, X. Long, B. Luo, A. Kulesza, J. Reichwagen, Y. Guo, WO 2012097510 (2012).

[133] C.A. Correia, K. Gilmore, D.T. McQuade, P.H. Seeberger, A Concise Flow Synthesis of Efavirenz, Angew. Chem. Int. Ed. 54 (2015) 4945-4948.

[134] S. Okusu, K. Hirano, Y. Yasuda, J. Tanaka, E. Tokunaga, H. Fukaya, N. Shibata, Alkynyl Cinchona Catalysts affect Enantioselective Trifluoromethylation for Efavirenz under Metal-Free Conditions, Org. Lett. 18 (2016) 5568-5571.

[135] A.E. Sorochinsky, T. Katagiri, T. Ono, A. Wzorek, J.L. Aceña, V.A. Soloshonok, Optical purifications via Self-Disproportionation of Enantiomers by achiral chromatography; Case study of a series of $\alpha-\mathrm{CF}_{3}$-containing secondary alcohols, Chirality 25 (2013) 365-368.

[136] J. Han, D.J. Nelson, A.E. Sorochinsky, V.A. Soloshonok, Self-Disproportionation of Enantiomers via Sublimation; New and Truly Green Dimension in Optical Purification, Curr. Org. Synth. 8 (2011) 310-317.

[137] During the production of this review we became aware of a related and complementary review; M. Inoue, Y. Sumii, N. Shibata, Contribution of Organofluorine Compounds to Pharmaceuticals, ACS Omega 5 (2020) 10633-10640. 